\title{
Estrogen Induces Axonal Outgrowth in the Nucleus Retroambiguus-Lumbosacral Motoneuronal Pathway in the Adult Female Cat
}

\author{
Veronique G. J. M. VanderHorst and Gert Holstege \\ Department of Anatomy and Embryology, Faculty of Medicine, University of Groningen, 9713 EZ Groningen, \\ The Netherlands
}

\begin{abstract}
In 1995, we discovered a new pathway in the cat, which originates from the nucleus retroambiguus (NRA) and terminates in a distinct set of lumbosacral hindlimb, axial, and pelvic floor motoneuronal cell groups [VanderHorst VGJM, Holstege G (1995) Caudal medullary pathways to lumbosacral motoneuronal cell groups in the cat: evidence for direct projections possibly representing the final common pathway for lordosis. J Comp Neurol 359:457-475]. The NRA is a compact group of interneurons located laterally in the caudal medulla oblongata. Its projection to lumbosacral motoneurons is thought to represent the final common pathway for male mounting and for female receptive or lordosis behavior. However, females only display lordosis behavior when they are in estrus, which suggests that the NRA-lumbosacral pathway is only active during estrus. This raised the question of whether estrogen affects this pathway. The effect of estrogen on the NRA-lumbosacral projection was studied light microscopically, using wheat-germ agglutinin horseradish peroxidase (WGA-HRP) as a tracer. The rubrospinal pathway served as control. The density of labeled NRA fibers in their target hindlimb motoneuronal cell groups ap-
\end{abstract}

The nucleus retroambiguus (NRA) is a compact group of interneurons in the lateral tegmentum of the caudal medulla and has been described in humans, cats, rats, hamsters, and birds (Olszewski and Baxter, 1954; Merrill, 1970; Paxinos and Watson, 1986; Holstege, 1989; Ellenberger and Feldman, 1990; Wild, 1993) (P. Gerrits, V. VanderHorst, and G. Holstege, unpublished observations). Anatomically as well as physiologically, the NRA has been shown to be involved in respiration, defecation, vomiting, and vocalization (Merrill, 1971, 1974; Feldman, 1986; Fukuda and Fukai, 1986; Miller et al., 1987, 1995; Holstege, 1989; Zhang et al., 1992). It receives projections from respiration-related neurons in the brainstem (Feldman, 1986; J. C. Smith et al., 1989; Gerrits and Holstege, 1996), and from the midbrain periaqueductal gray (PAG) (Holstege, 1989; VanderHorst and Holstege, 1996). The PAG plays a crucial role in the integration of survival behavior such as

\footnotetext{
Received July 11, 1996; revised Oct. 21, 1996; accepted Nov. 5, 1996.

We thank Henk de Weerd for his work on the electron microscopic study; Ellie Meijer and Klaas van Linschoten for their histotechnical support; Peter van der Sijde for photographic assistance; and Han van der Want (Laboratory for Cell Biology and Electronmicroscopy, University of Groningen) and Jan Carel Holstege (Department of Anatomy, Erasmus University, Rotterdam) for their advise on the electron microscopic study.

Correspondence should be addressed to Dr. Veronique G. J. M. VanderHorst, Department of Anatomy, 0ostersingel 69, 9713 EZ Groningen, The Netherlands. Copyright (C) 1997 Society for Neuroscience $0270-6474 / 97 / 171122-15 \$ 05.00 / 0$
}

peared abundant in estrous and very weak in nonestrous cats. Such differences were not found in the rubrospinal pathway. For electron microscopical study, the NRA projection to the semimembranosus motoneuronal cell group was selected. In this cell group, an almost ninefold increase of labeled profiles was found in estrous versus nonestrous cats. Moreover, the semimembranous motoneuronal cell group contained labeled growth cones in estrous, but not in nonestrous, cats. The present study is the first to show that estrogen induces axonal outgrowth of a precisely identified pathway in the adult mammalian central nervous system. The possible mechanisms underlying this outgrowth are discussed.

Key words: estrogen; motoneuron; sexual behavior; spinal cord; nucleus retroambiguus; caudal medulla; cat; female; plasticity; sprouting; growth cone; ventral horn; lordosis behavior; sex steroid; WGA-HRP; hindlimb; muscle; semimembranosus; pelvic floor; iliopsoas; adductor longus; biceps femoris defensive and aggressive reactions as well as mating (Sakuma and Pfaff, 1979a,b; Bandler et al., 1991; Ogawa et al., 1991).

In the female as well as in the male cat (VanderHorst et al., 1994; VanderHorst and Holstege, 1995, 1996, 1997b), the NRA projects directly to lumbosacral motoneuronal cell groups innervating a distinct set of hindlimb, axial, and pelvic floor muscles. Combined action of this set of muscles in the female does not serve motor activities as stepping, jumping, scratching, running, or other daily activities, but underlies aspects of the receptive posture during mating. Such behavior consists of elevation of the lower back (lordosis), rhythmic movements of the hindlimbs (treading), and lateral deviation of the tail (Michael, 1960). This led us to postulate that in female cats, the NRA-lumbosacral motoneuronal projection forms the final common pathway for lordosis behavior (VanderHorst and Holstege, 1995). Electromyographic studies are currently undertaken by this lab to provide evidence for our hypothesis.

Female reproductive behavior is not displayed in the absence of estrogen, whereas in estrous animals, it is prominently present (Beach, 1948; Young, 1961; Clark and Mani, 1994). If the NRA-lumbosacral motoneuronal projection represents the final common pathway for lordosis behavior, the question arises of whether estrogen has an effect on this pathway. Therefore, the pathway was studied light and electron microscopically both in estrous and in nonestrous cats. The results 
Table 1. Overview of the NRA and red nucleus cases

\begin{tabular}{|c|c|c|c|c|c|c|c|}
\hline \multirow[b]{2}{*}{ NRA } & \multirow[b]{2}{*}{ Hemisection } & \multirow[b]{2}{*}{ WGA-HRP (\%) } & \multirow{2}{*}{$\begin{array}{l}\text { Number of } \\
\text { injections }\end{array}$} & \multirow[b]{2}{*}{$\mathrm{nl} /$ injection } & \multirow[b]{2}{*}{ Total (nl) } & \multicolumn{2}{|l|}{ Density } \\
\hline & & & & & & LM & EM \\
\hline \multicolumn{8}{|c|}{ Nonestrous } \\
\hline \multicolumn{8}{|c|}{ Natural nonestrous } \\
\hline 2237 & - & 5 & 3 & 30 & 90 & \pm & ns \\
\hline 2251 & - & 5 & 2 & 30 & 60 & \pm & 25 \\
\hline 2256 & - & 5 & 5 & 40 & 200 & \pm & 9 \\
\hline 2258 & - & 5 & 2 & 25 & 50 & \pm & ns \\
\hline 2267 & - & 2.5 & 2 & 30 & 60 & \pm & ns \\
\hline 2271 & - & 2.5 & 3 & 30 & 90 & \pm & $\mathrm{ns}$ \\
\hline 2286 & + & 2.5 & 5 & 45 & 225 & \pm & ns \\
\hline \multicolumn{8}{|c|}{ Ovariectomized nonestrogen-treated } \\
\hline 2296 & + & 2.5 & 3 & 50 & 150 & \pm & ns \\
\hline 2308 & + & 2.5 & 4 & 50 & 200 & \pm & 12 \\
\hline 2324 & + & 2.5 & 3 & 40 & 120 & + & 38 \\
\hline \multicolumn{8}{|l|}{ Estrous } \\
\hline \multicolumn{8}{|c|}{ Natural estrous } \\
\hline 2288 & + & 2.5 & 4 & 40 & 160 & ++++ & 281 \\
\hline 2337 & + & 2.5 & 4 & 30 & 120 & +++ & 157 \\
\hline \multicolumn{8}{|c|}{ Ovariectomized estrogen-treated } \\
\hline 2299 & + & 2.5 & 3 & 50 & 150 & +++ & ns \\
\hline 2307 & + & 2.5 & 4 & 50 & 200 & +++ & 112 \\
\hline 2320 & + & 2.5 & 1 & 30 & 30 & ++ & ns \\
\hline 2353 & + & 2.5 & 4 & 40 & 160 & +++ & 183 \\
\hline 2361 & + & 2.5 & 4 & 30 & 120 & ++++ & ns \\
\hline \multicolumn{8}{|c|}{ Red nucleus } \\
\hline \multicolumn{8}{|c|}{ Nonestrous } \\
\hline \multicolumn{8}{|c|}{ Natural nonestrous } \\
\hline 2245 & - & 5 & 1 & 15 & 15 & +++++ & ns \\
\hline \multicolumn{8}{|c|}{ Ovariectomized nonestrogen-treated } \\
\hline 2362 & - & 2.5 & 6 & 25 & 150 & ++++++ & ns \\
\hline \multicolumn{8}{|l|}{ Estrous } \\
\hline \multicolumn{8}{|c|}{ Ovariectomized estrogen-treated } \\
\hline 2310 & + & 2.5 & 2 & 30 & 60 & +++++ & ns \\
\hline 2363 & - & 2.5 & 6 & 25 & 150 & ++++++ & ns \\
\hline
\end{tabular}

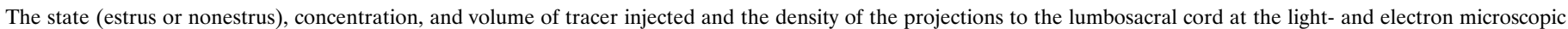
level are indicated. ns, Not studied; LM, light microscopic level; EM, electron microscopic level.

indicate that estrogen induces axonal outgrowth of NRA fibers to their target motoneurons in the lumbosacral cord.

\section{MATERIALS AND METHODS}

\section{Ovariohysterectomy and estrogen treatment}

$N R A$ series. Anterograde tracing experiments were performed in 17 adult female cats (Table 1). Eight females were ovariohysterectomized 4-5 weeks before the tracer injection. Five of them were estrogen-treated for $7-10 \mathrm{~d}$ before the tracing experiment, receiving daily subcutaneous injections of estradiol benzoate dissolved in oil (Mycofarm, $0.02 \mathrm{mg} / \mathrm{kg} / \mathrm{d}$ ). After $3 \mathrm{~d}$ of treatment, they started to display the typical lordosis behavior when tapping the lower back or presenting them to a male cat. Estrogen treatment was continued until to the day of perfusion. The remaining three ovariectomized control cats received no estrogen. Progesterone was not administered, because cats are reflex ovulators in which progesterone levels start to rise only after intromission by the male or intense vaginocervical stimulation (Dawson and Friedgood, 1940).

Of the remaining nine nonovariectomized cats, two were in full estrus, i.e., displayed the complete pattern of estrous behavior during 3-4 d before the tracer injection. The other seven cats showed no signs of estrous behavior in the 2 weeks before or the $3 \mathrm{~d}$ after the tracer injection.

Red nucleus control series. In four females, the rubrospinal projections in estrous and nonestrous females were studied (Table 1). Three cases were ovariectomized, of which two did and one did not receive estrogen treatment before the tracer injections. The remaining natural case did not display estrous behavior in the 2 weeks before or the $3 \mathrm{~d}$ after the tracer injection.

\section{WGA-HRP injections}

NRA series. The distribution of the NRA-lumbosacral neurons in the cat have been described by VanderHorst and Holstege (1995) (see also Fig. 1). Because the NRA extends rostrocaudally over a length of 6-7 mm, multiple needle penetrations were necessary to inject wheat germ agglutinin-horseradish peroxidase (WGA-HRP, Sigma) throughout its rostrocaudal extent. This reduced the possibility that differences in the injection site would result in differences in the NRA-lumbosacral projections among the cases. WGA-HRP was pressure-injected via a glass micropipette using a picopump after dorsal approach and exposure of the caudal medulla. Except for cases 2237, 2251, 2256, 2258, 2267, and 2271, the injections were preceded by an ipsilateral $\mathrm{C} 2$ hemisection, which interrupted all ipsilaterally descending, non-NRA pathways to the spinal cord (VanderHorst and Holstege, 1995). The hemisections were made by aspiration with a glass pipette.

Red nucleus control series. To rule out the possibility that estrogen has a similar effect on other descending pathways, the rubrospinal tract was chosen as a control pathway. In two cases (2245 and 2310), small WGAHRP injections were made in the red nucleus, and in two other cases 


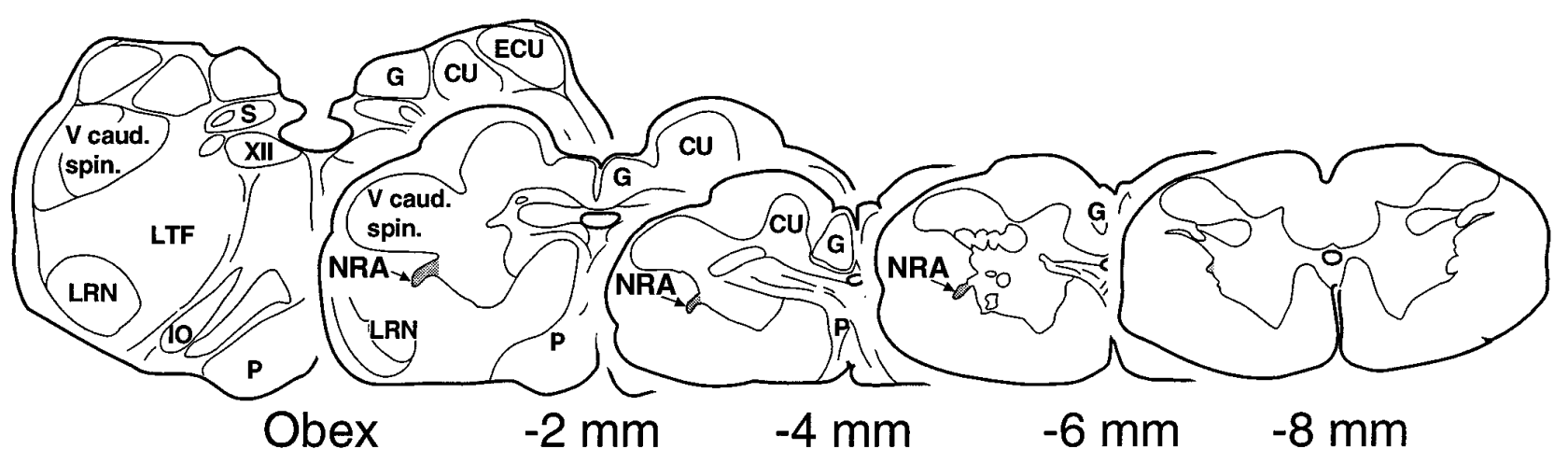

Figure 1. Schematic drawings showing the location of the NRA-lumbosacral neurons in the caudal medulla oblongata. Note that it is most prominent between 2 and $6 \mathrm{~mm}$ caudal to the obex, where it can be easily recognized as a protrusion of gray matter into the white matter (see also VanderHorst and Holstege, 1995). $C U$, Cuneate nucleus; $E C U$, external cuneate nucleus; $G$, gracile nucleus; $I O$, inferior olive; $L R N$, lateral reticular nucleus; $L T F$, lateral tegmental field; $N R A$, nucleus retroambiguus; $P$, pyramidal tract; $S$, solitary complex; $V$ caud. spin., caudal spinal trigeminal complex; XII, hypoglossal nucleus.

(2362 and 2363), the red nucleus was injected with similar volumes of tracer as used in the NRA-injected cases (Table 1). In case 2310, before the injection an ipsilateral $\mathrm{C} 2$ hemisection was made.

\section{General surgical and histological procedures}

The surgical procedures, pre- and postoperative care, and handling and housing of the animals were carried out according to the protocols approved by the Faculty of Medicine of the University of Groningen. The animals were anesthetized with an initial dose of ketamine, $0.1 \mathrm{ml} / \mathrm{kg}$, i.m. (Nimatek, A.U.V.) and xylazine hydrochloride, $0.1 \mathrm{ml} / \mathrm{kg}$, i.m. (Sedamun, A.U.V.). Subsequently, they were artificially ventilated under mixed halothane-nitrous oxide anesthesia. During surgery, ECG and temperature were monitored.

After 3 d survival time, the animals were initially anesthetized with ketamine and xylazine hydrochloride followed by an intraperitoneal injection of $6 \mathrm{ml}$ of $6 \%$ pentobarbital sodium (Nembutal). Subsequently, they were transcardially perfused with 21 of heparinized saline at $35^{\circ} \mathrm{C}$, followed by 21 of fixative containing $2 \%$ glutaraldehyde/ $1 \%$ paraformaldehyde in $0.1 \mathrm{M}$ phosphate buffer, $\mathrm{pH}$ 7.2-7.4, at room temperature. Brains and spinal cords were removed and post-fixed for 1-2 hr. In the cases exclusively used for light microscopy, $4 \%$ sucrose was added to the fixative, and the tissue was stored overnight in $25 \%$ sucrose buffered phosphate at $4^{\circ} \mathrm{C}$. After perfusion, brain and spinal cord were removed, and the injection site was cut on a freezing microtome into $40-\mu \mathrm{m}$-thick transverse sections and incubated using a standard diaminobenzidine (DAB, Sigma) procedure. The hemisected segments were processed to verify that the hemisections were complete. Finally, the sections were mounted on slides, dehydrated, and coverslipped with DePeX mounting medium (Brunschwig chemie).

\section{Light microscopy}

The L3-S3 segments were cut on a freezing microtome into $40-\mu \mathrm{m}$-thick transverse sections, except in eight cases $(2251,2256,2288,2307,2308$, 2324,2337 , and 2353), which were cut on a vibratome into $60 \mu \mathrm{m}$ sections. Every fourth section was processed using the tetramethylbenzidine (TMB, Sigma) procedure according to Mesulam (1982). Sections of the NRA-injected cases 2296 and 2299 and 2307 and 2308 and of the red nucleus cases 2362 and 2363 were processed in the same TMB procedure to eliminate differences in staining due to different reaction conditions. The density of anterograde labeling in the spinal cord was microscopically examined with a Zeiss Axioskop under combination of polarized light and dark-field condensor. Using a new, detailed overview of the spatial location of lumbosacral motoneuronal cell groups (VanderHorst and Holstege, 1997), it could be determined with great precision which of these cell groups received NRA afferents. Photomicrographs of representative sections were taken.

\section{Electron microscopy}

Cases 2251, 2256, 2288, 2307, 2308, 2324, 2337, and 2353 were examined light- and electron microscopically. The L3-S3 segments of these cases were cut on a vibratome. Every third section was incubated with TMB and ammonium heptamolybdate overnight (Olucha et al., 1985). The next day, they were processed using the slow-osmication method for postfixation of Henry et al. (1985). The tissue was stained en bloc in $1 \%$ uranylacetate in aquabidest, and the slabs were dehydrated in graded series of alcohol and embedded in Epon between dimethyldichlorosilanecoated glass slides (Vinores et al., 1984).

Using a new, detailed overview of the spatial location of lumbosacral motoneuronal cell groups, it could be determined with great precision which of these cell groups received NRA afferents. A selection was made of sections containing anterogradely labeled fibers in the semimembranosus motoneuronal cell group. This is a compact cell group that does not overlap with other motoneuronal cell groups, except for its most rostral and most caudal poles (Romanes, 1951, 1964) (VanderHorst and Holstege 1997a), which made it possible to identify it in unstained sections. The selected tissue was cut into ultrathin sections $(60 \mathrm{~nm})$ and studied using electron microscopy. To determine the density of labeled terminal profiles per area, in each case the labeled terminal profiles were counted in 32 grid squares covering the semimembranosus motoneuronal cell group, each grid square measuring $10,000 \mu \mathrm{m}^{2}$. The counts were made blind to the condition of the animals. The symmetry or asymmetry of the synaptic membrane specialization and the content of the labeled profiles were established. In cases 2324 and 2337, the perimeter of labeled terminal profiles and the length of postsynaptic densities were measured.

\section{RESULTS}

\section{Location and size of the injection sites in the NRA}

In all 17 cases, the injections involved the NRA over a considerable rostrocaudal extent (Fig. 2, Table 1). The hemisections were complete and did not extend across the midline. Examples of the DAB injection sites are shown in cases 2288 and 2324 (Fig. 3).

\section{Nonestrous cases}

\section{Light microscopy}

In the lumbosacral cord of all natural and ovariectomized nonestrous cases (Table 1, Fig. 2), the abdominal wall and pelvic floor motor nuclei received a substantial projection (Fig. 4) (see Holstege and Kuypers, 1982; Feldman et al., 1985; Holstege and Tan, 1987; Miller et al., 1989; Holstege, 1989). In addition, labeled fibers terminated in the hindlimb motoneuronal cell groups (Fig. 5 , left), but they were so sparse that in single sections it was not possible to determine which hindlimb motor nuclei were their main target. However, superposition of six consecutive sections, which were taken from a series in which every fourth section was collected, revealed a distinct projection pattern to the motoneuronal cell groups innervating the muscles iliopsoas, adductor longus, semimembranosus, semitendinosus, biceps femoris anterior and posterior, external anal and urethral sphincter, levator 


\section{Non-estrous}
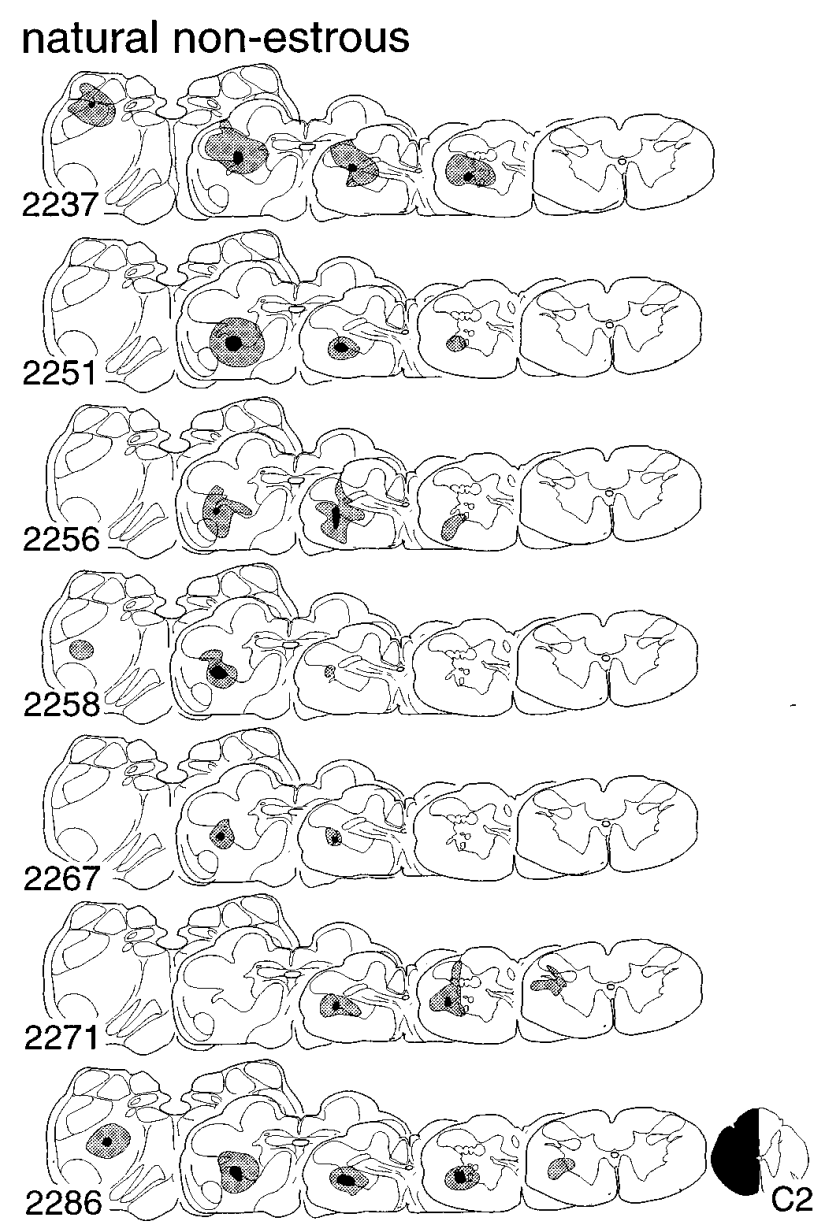

\section{ovariectomized-non estrogen treated}
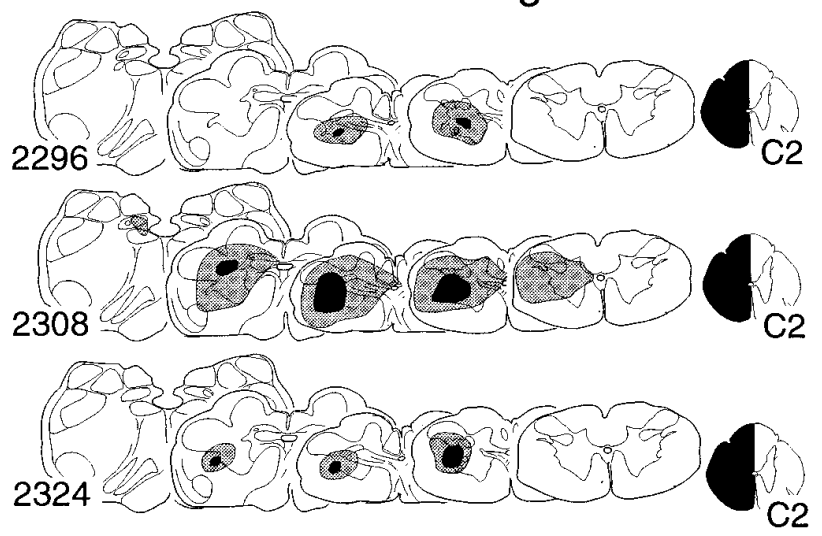

ani, abductor caudae internus, medial longissimus, and multifidi (VanderHorst and Holstege, 1995).

\section{Electron microscopy}

In the semimembranosus motoneuronal cell group of cases 2251, 2256,2308 , and 2324 , a total number of $25,9,12$, and 38 labeled

\section{Estrous}

natural estrous

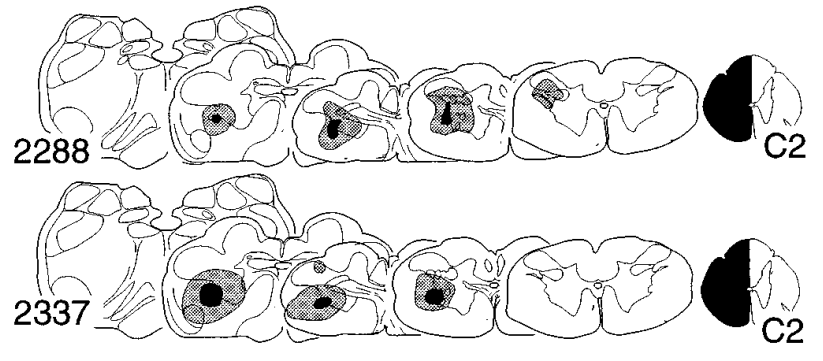

ovariectomized-estrogen treated

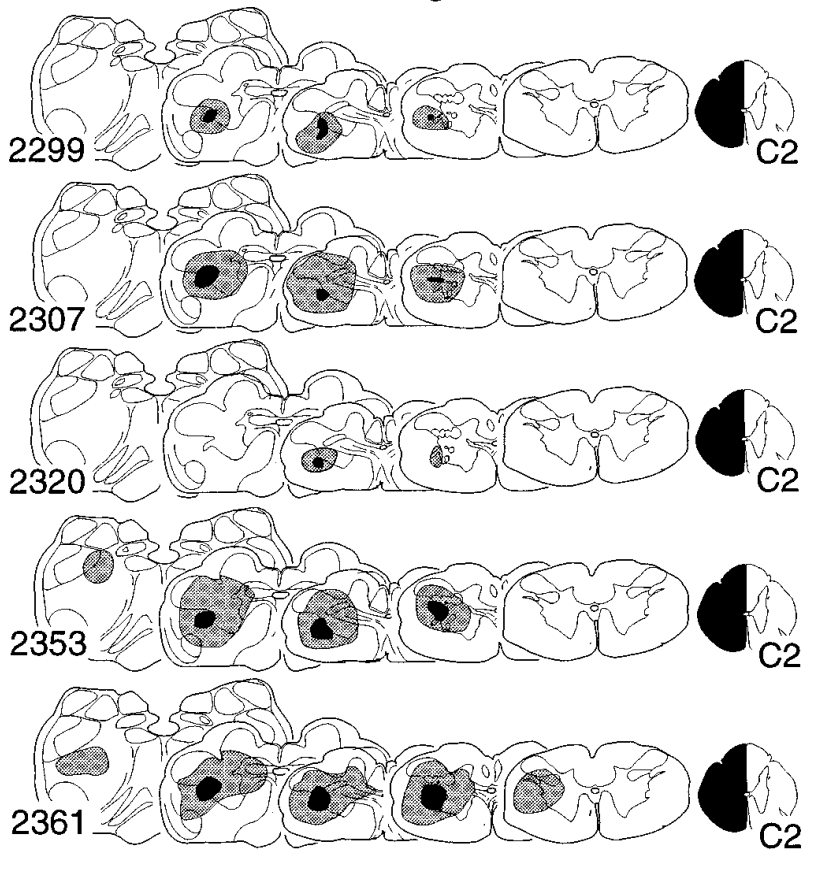

Figure 2. Schematic drawings of hemisections and WGA-HRP injection sites involving the NRA in estrous and nonestrous cases. The core of the injections is indicated in black. terminal profiles were counted per 32 grid squares $\left(320,000 \mu \mathrm{m}^{2}\right)$, respectively (Table 1). Synapses, which were all asymmetrical, were present in $22 \%$ of these profiles. Furthermore, $66 \%$ of the labeled profiles contained exclusively spherical vesicles, whereas $13 \%$ contained spherical as well as a few dense-cored vesicles (Table 2). Of the remaining $22 \%$, the vesicle content could not be 

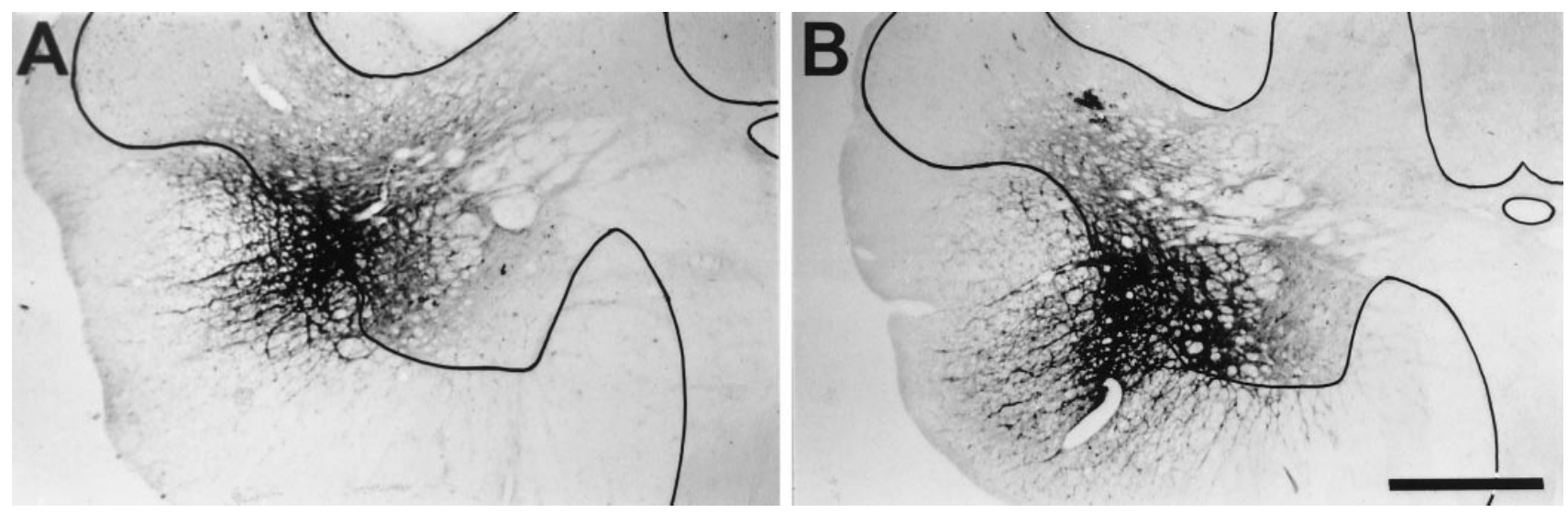

Figure 3. Photomicrographs showing examples of the WGA-HRP injection sites in cases 2324 (left) and 2288 (right). Scale bar, 1 mm.

\section{Non-estrous}
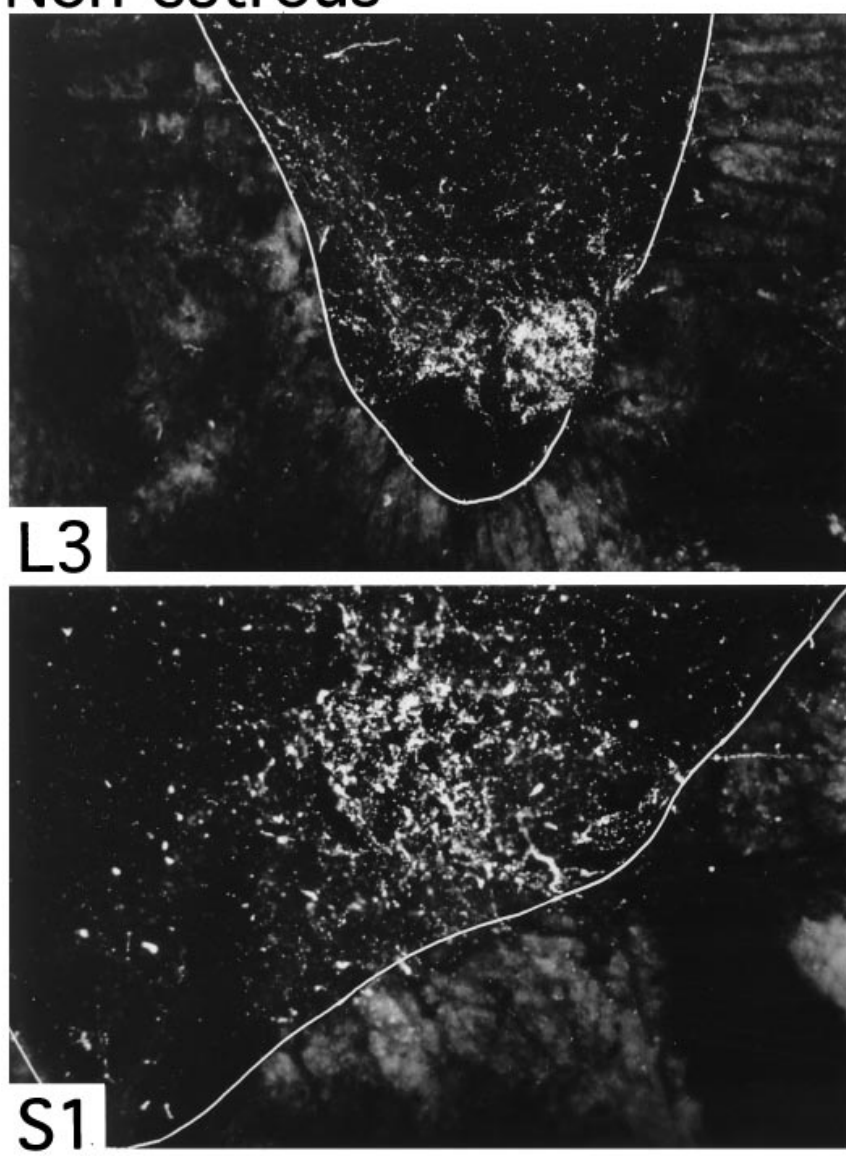

\section{Estrous}
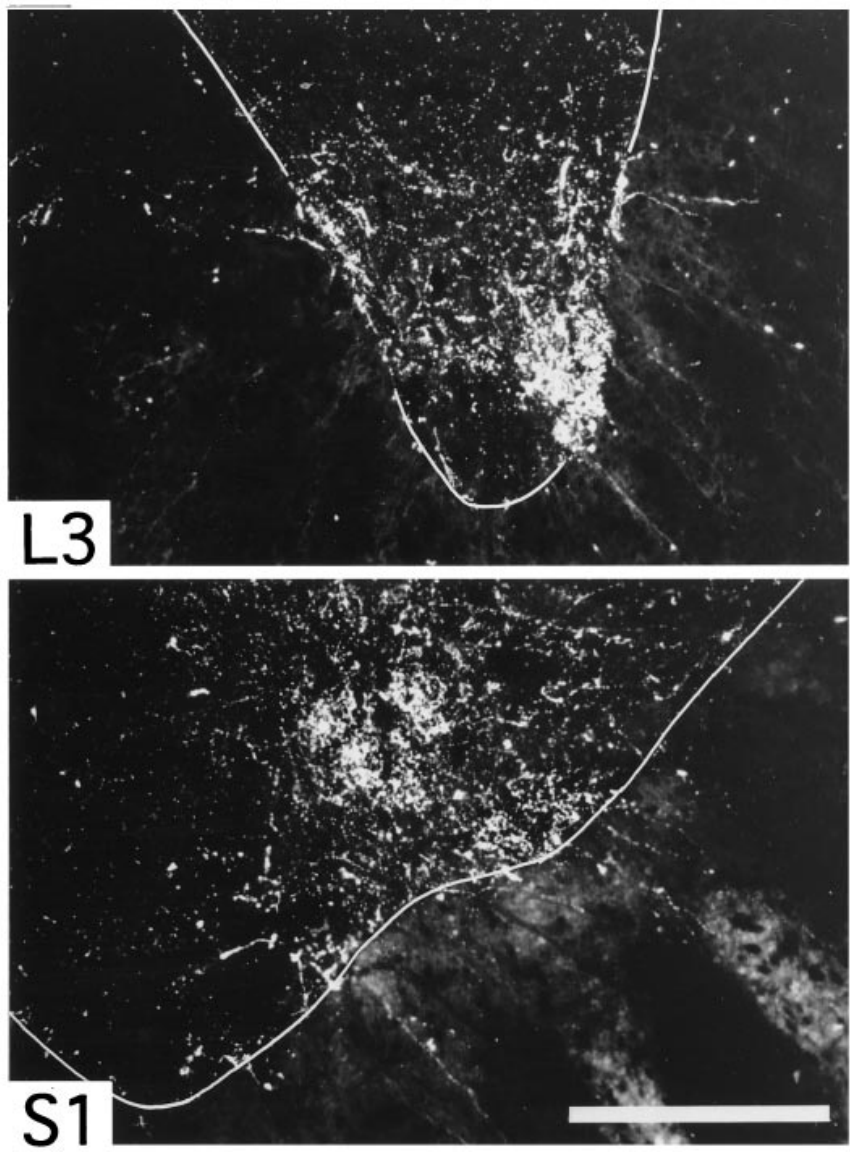

Figure 4. Dark-field polarized light photomicrographs showing labeled NRA fibers in the abdominal wall motoneuronal cell groups at the L3 level and in Onuf's nucleus at the S1 level in nonestrous (case 2324, left) and estrous cats (case 2288, right). Note that the NRA projections to the abdominal wall and pelvic floor motor nuclei are slightly denser in estrous than in nonestrous. Scale bar, $400 \mu \mathrm{m}$.

identified. Apart from spherical and dense-cored vesicles, labeled terminal profiles frequently contained some clustered mitochondria (Fig. 6, left). Labeled profiles with flattened or pleiomorphic vesicles were never observed.

In one case (2324), the average perimeter of labeled terminal profiles was determined and amounted to $7.41 \mu \mathrm{m}(n=38$; ranging from 3.29 to $14.43 \mu \mathrm{m}$ ). On average, $6.9 \%$ of it was covered by synaptic junctions. Labeled terminal profiles predom- inantly contacted dendrites (Fig. 6, left) and only very occasionally neuronal somata.

\section{Estrous cases}

\section{Light microscopy}

In all natural and ovariectomized estrous cases, the NRA-lumbosacral projection was remarkably dense. In sharp contrast to the nonestrous cases, the projections to motoneuronal cell groups 


\section{Non-estrous}
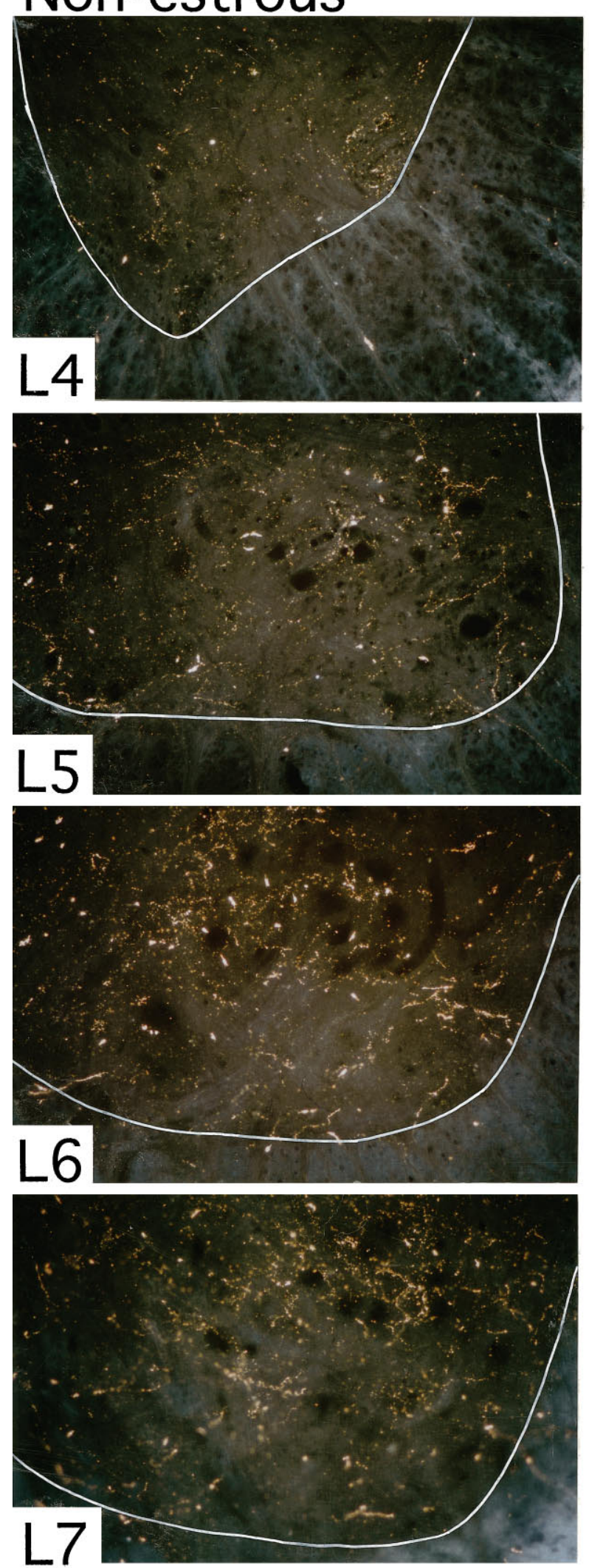

\section{Estrous}
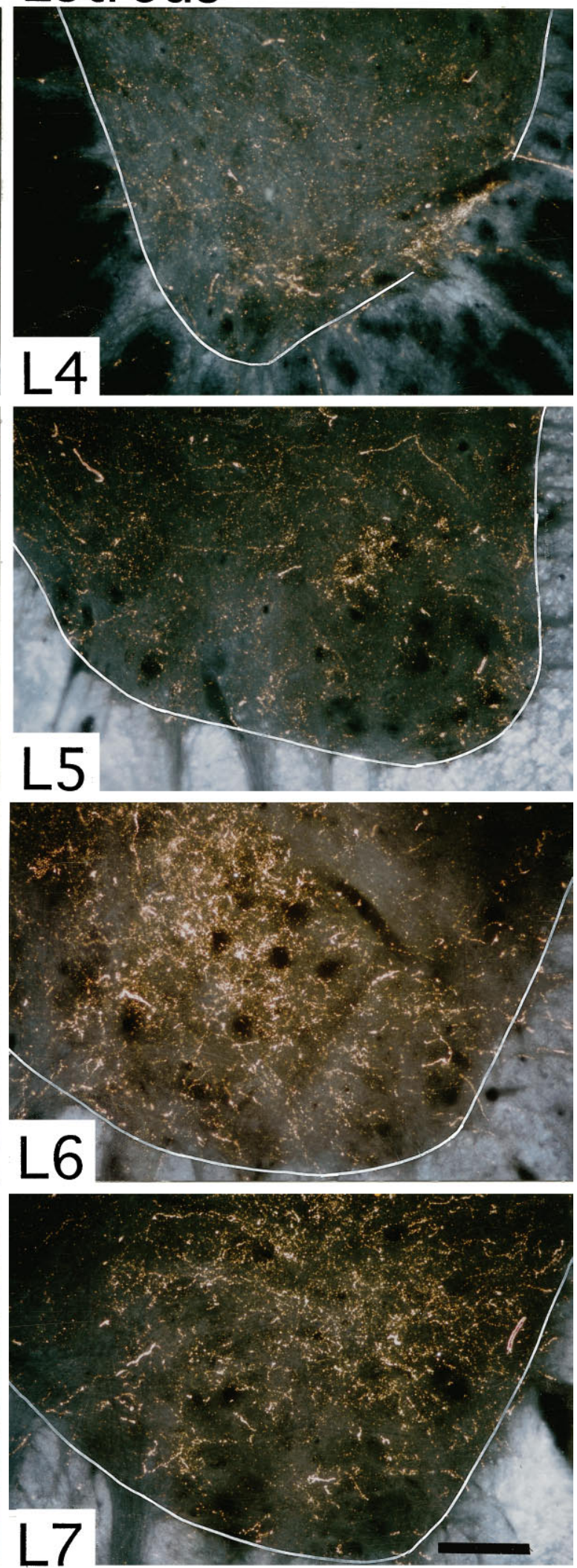

Figure 5. Dark-field polarized light photomicrographs of labeled NRA fibers in the motoneuronal cell groups of the iliopsoas ( $L 4)$, adductor longus (L5), semimembranosus $(L 6)$, and biceps anterior $(L 7)$ in nonestrous case 2324 (left) and estrous case 2288 (right). Note the large difference in the density of NRA fibers between the nonestrous and the estrous case. Scale bar, $300 \mu \mathrm{m}$. 
Table 2. Labeled NRA profiles in the semimembranosus motoneuronal cell group of nonestrous and estrous cases

\begin{tabular}{|c|c|c|c|c|c|c|c|c|c|c|c|}
\hline & \multirow{3}{*}{$\begin{array}{l}\text { Total number } \\
\text { of labeled } \\
\text { terminals }\end{array}$} & \multicolumn{4}{|c|}{ Labeled terminals with asymmetrical synapses } & \multicolumn{4}{|c|}{$\begin{array}{l}\text { Labeled terminals in which no synapse } \\
\text { was observed }\end{array}$} & & \\
\hline & & \multicolumn{2}{|c|}{ Sperical vesicles } & \multicolumn{2}{|c|}{$\begin{array}{l}\text { Spherical and } \\
\text { dense-core vesicles }\end{array}$} & \multicolumn{2}{|c|}{ Spherical vesicles } & \multicolumn{2}{|c|}{$\begin{array}{l}\text { Spherical and } \\
\text { dense-core vesicles }\end{array}$} & \multicolumn{2}{|c|}{$\begin{array}{l}\text { Nonidentifiable } \\
\text { labeled terminals }\end{array}$} \\
\hline & & Number & $(\%)$ & Number & $(\%)$ & Number & $(\%)$ & Number & $(\%)$ & Number & $(\%)$ \\
\hline Nonestrous $(n=4)$ & 84 & 14 & $(17)$ & 4 & $(5)$ & 41 & $(49)$ & 7 & $(8)$ & 18 & $(21)$ \\
\hline Estrous $(n=4)$ & 732 & 67 & (9) & 33 & (5) & 398 & $(54)$ & 45 & (6) & 189 & $(26)$ \\
\hline
\end{tabular}

In each case, a total area of $320,000 \mu \mathrm{m}^{2}$ was examined, covering the same region of the cord.

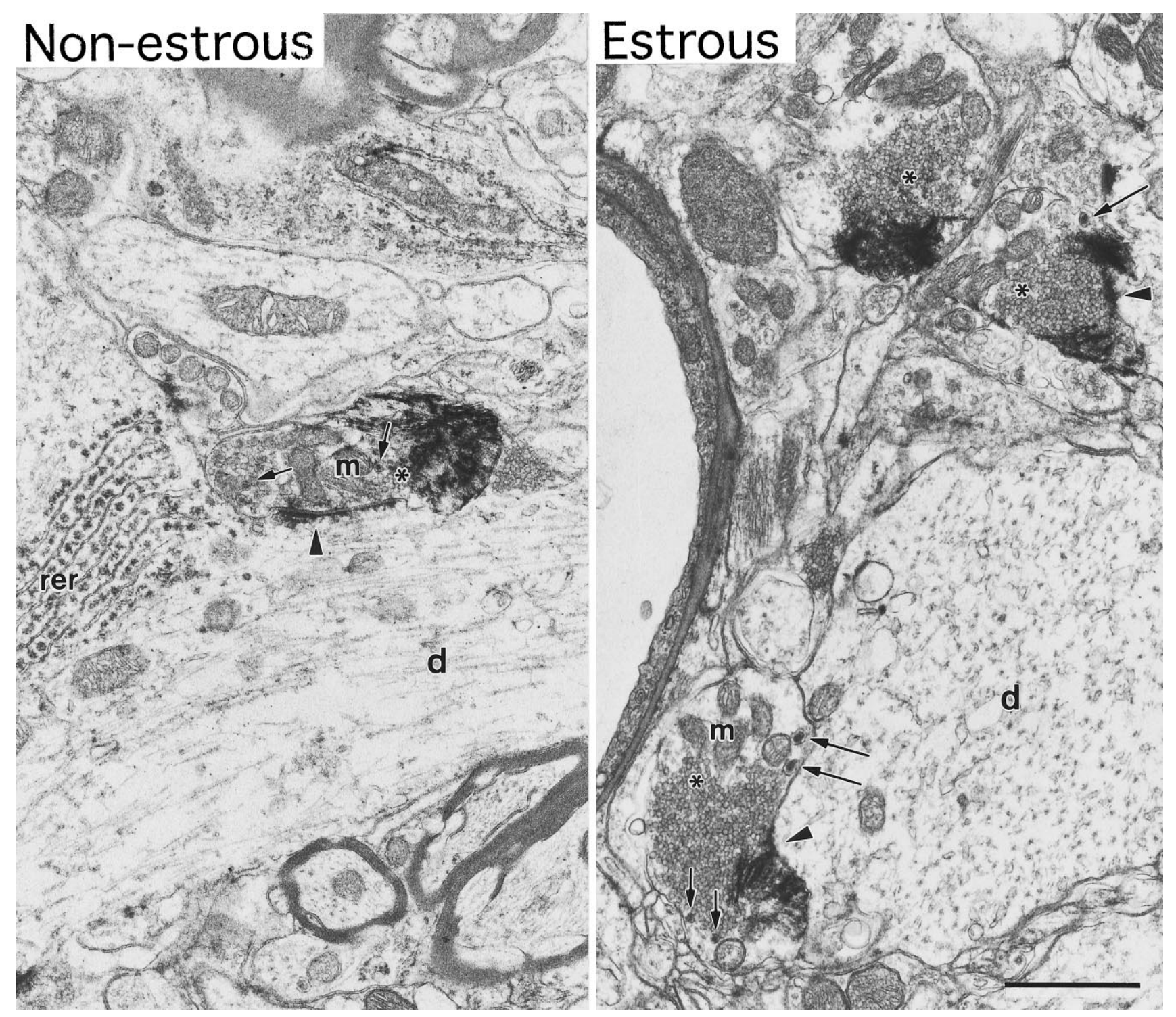

Figure 6. Electronmicrographs showing examples of labeled NRA profiles in the semimembranosus motoneuronal cell group of nonestrous case 2324 (left) and estrous case 2337 (right). In the nonestrous case, a labeled axo-dendritic profile is shown with closely packed spherical vesicles (asterisk), dense-core vesicles (small arrows), a few mitochondria $(m)$, and an asymmetric synaptic junction (arrowhead). The terminal is located at the initial segment of a dendrite $(d)$, which contains a few cisternae of endoplasmic reticulum with ribosomes (rer). In the estrous case, three large labeled axo-dendritic terminals are present with densely packed spherical vesicles (asterisk) and some dense-core (small arrows) and large granulated vesicles (large arrows). Two of them exhibit asymmetrical synaptic membrane specializations (arrowheads). Scale bar, $1 \mu \mathrm{m}$.

innervating the iliopsoas, adductor longus, semimembranosus, semitendinosus, biceps femoris anterior and posterior, and levator ani/abductor caudae internus were very prominent and could be easily discerned in single sections (Fig. 5, right). The differences between estrous and nonestrous cases in respect to the density of projections to the abdominal or pelvic floor motoneuronal cell groups were less apparent. These projections are prominent in estrous and in nonestrous cases (Fig. 4). 


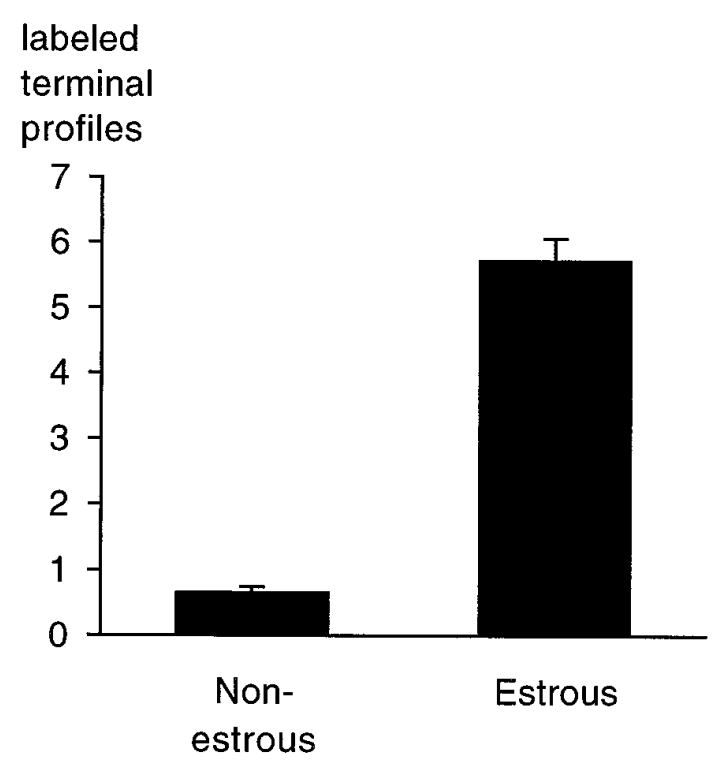

Figure 7. The mean \pm SEM number of labeled terminal profiles $/ 10,000$ $\mu \mathrm{m}^{2}$ in the groups of nonestrous and estrous cases. The density of labeled profiles differs significantly ( $p<0.025$; Wilcoxon-Mann-Whitney test).

Among the cases of the estrous group, some differences in density of the NRA-lumbosacral projection were present. In natural estrous case 2288 and in ovariectomized estrogen-treated case 2361, the projections were extremely strong. In case 2320 , with a small injection in the NRA, labeled fibers were not as numerous as in the other estrous cases, but still far outnumbered the NRA fibers in the nonestrous cases, including those with large NRA injections (Fig. 2, Table 1).

\section{Electron microscopy}

The number of labeled terminals per $320,000 \mu \mathrm{m}^{2}$ in the semimembranosus motoneuronal cell group of estrous cases 2288, 2307,2353 , and 2337 amounted to $281,112,183$, and 157, respectively (Table 1). The average number of labeled terminal profiles per grid square differed significantly between the group of estrous and the group of nonestrous cases (Wilcoxon-Mann-Whitney test, $p<0.025$ ) (Fig. 7). In 14\% of the labeled terminal profiles in the four estrous cases, synapses were observed, which were all asymmetrical. Of the labeled profiles, $63 \%$ contained spherical vesicles and $11 \%$ spherical as well as dense-cored vesicles. In the remaining $26 \%$, the vesicle content could not be identified (Table 2). No labeled terminals with flattened pleiomorphic vesicles were observed. The labeled terminal profiles primarily contacted dendrites and only very occasionally neuronal somata.

In case 2337, the average perimeter of the labeled terminal profiles was $9.49 \mu \mathrm{m}$ ( $n=73$; ranging from 5.25 to $22.25 \mu \mathrm{m})$, which is 1.28 times larger than in the nonestrous case 2324 (7.41 $\mu \mathrm{m})$. In these labeled profiles, synaptic complexes on average formed $5.0 \%$ of the perimeter, which is less than in the nonestrous case $2324(6.9 \%)$.

In the area under examination (the semimembranosus motoneuronal cell group), the absolute number of labeled terminals displaying synapses was much higher in the estrous cases as compared with nonestrous cases (100 and 18, respectively) (see Table 2). The percentage of labeled profiles showing one or more synaptic junctions was larger in nonestrous cases than in estrous cases (21 and 14\%, respectively).

In all estrous cases, but not in nonestrous cases, very large labeled structures were found that contained large quantities of tightly packed mitochondria $(297,159,86$, and 32 mitochondria per $35.6,25.4,12.9$, and $8.5 \mu \mathrm{m}^{2}$ ), and some agranular reticulum, a few coated, dense-core, and large granulated vesicles, lysosomes, electron-dense particles, and microtubuli (Figs. 8, left, 9). The mitochondria had a smaller diameter and were more elongated than the mitochondria in adjacent structures (Figs. 8, 9). Similar structures have been described as the proximal or central part of neuronal growth cones in the developing CNS (Tennyson, 1970; Yamada et al., 1971; Bunge et al., 1973; Bridgman and Dailey, 1989; Davis et al., 1992), which leads to the conclusion that the large labeled profiles in the present material $(4.6 \%$ of the labeled profiles in the four estrous cases) represent the proximal parts of growth cones.

Furthermore, labeled, large terminal-like profiles were observed that contained small-diameter elongated mitochondria, cisternae of agranular reticulum, spherical synaptic vesicles, dense-cored vesicles, large granulated vesicles, vacuoles, coated vesicles, and a few microtubules and neurofilaments (Figs. 8, 10). Similar assemblies of organelles have been described in growth cones and immature terminals (Tennyson, 1970; Yamada et al., 1971; Bunge et al., 1973; Vaughn and Sims, 1978; Knyihar-Csillik et al., 1986; Bridgeman and Dailey, 1989; Peters et al., 1991). The presence of large numbers of coated vesicles in the NRA terminals suggests a high level of membrane turnover (Rees et al., 1976), which is thought to be involved in the formation of axonal collaterals (Vaughn and Sims, 1978). At the postsynaptic site, mitochondria, multivesicular bodies, coated vesicles and polyribosomes were found frequently (Fig. 10). Postsynaptically located polyribosomes, which have been described to be particularly prominent during periods of synapse growth, might synthesize proteins that are important for axonal outgrowth or maturation of the synaptic junction (Steward and Falk, 1986, 1991).

In conclusion, many of the labeled NRA profiles in estrous cases contain growth cones and immature terminals, which indicates that outgrowth of NRA axons takes place when the animal is in estrus.

\section{Rubrospinal control series}

In four cases, WGA-HRP was injected in the red nucleus and surrounding tegmentum (Fig. 11). In all these cases, the density of anterogradely labeled fibers in the intermediate zone of the lumbar enlargement was denser than in the motoneuronal cell groups of NRA-injected cases and was easily visible using bright-field illumination. The two large injections resulted in a slightly stronger projection (nonestrous case 2362 and estrous case 2363) than the smaller red nucleus injections (nonestrous case 2245 and estrous case 2310). However, comparing the estrous with the nonestrous cases with similar injection sites did not reveal any difference in the density of labeling at the light microscopical level.

\section{DISCUSSION}

The present results demonstrate that the density of the pathway from the NRA to hindlimb motoneuronal cell groups shows significant estrogen-related differences in adult female cats. Electron microscopical results confirmed the light microscopical observations, demonstrating an almost ninefold increase in the number of NRA terminal profiles in estrous cases. These major differences cannot be fully explained by the small differences in the size of NRA profiles in estrous and nonestrous cases (estrous vs nonestrous $=1.28: 1)$. The finding of labeled axonal growth 


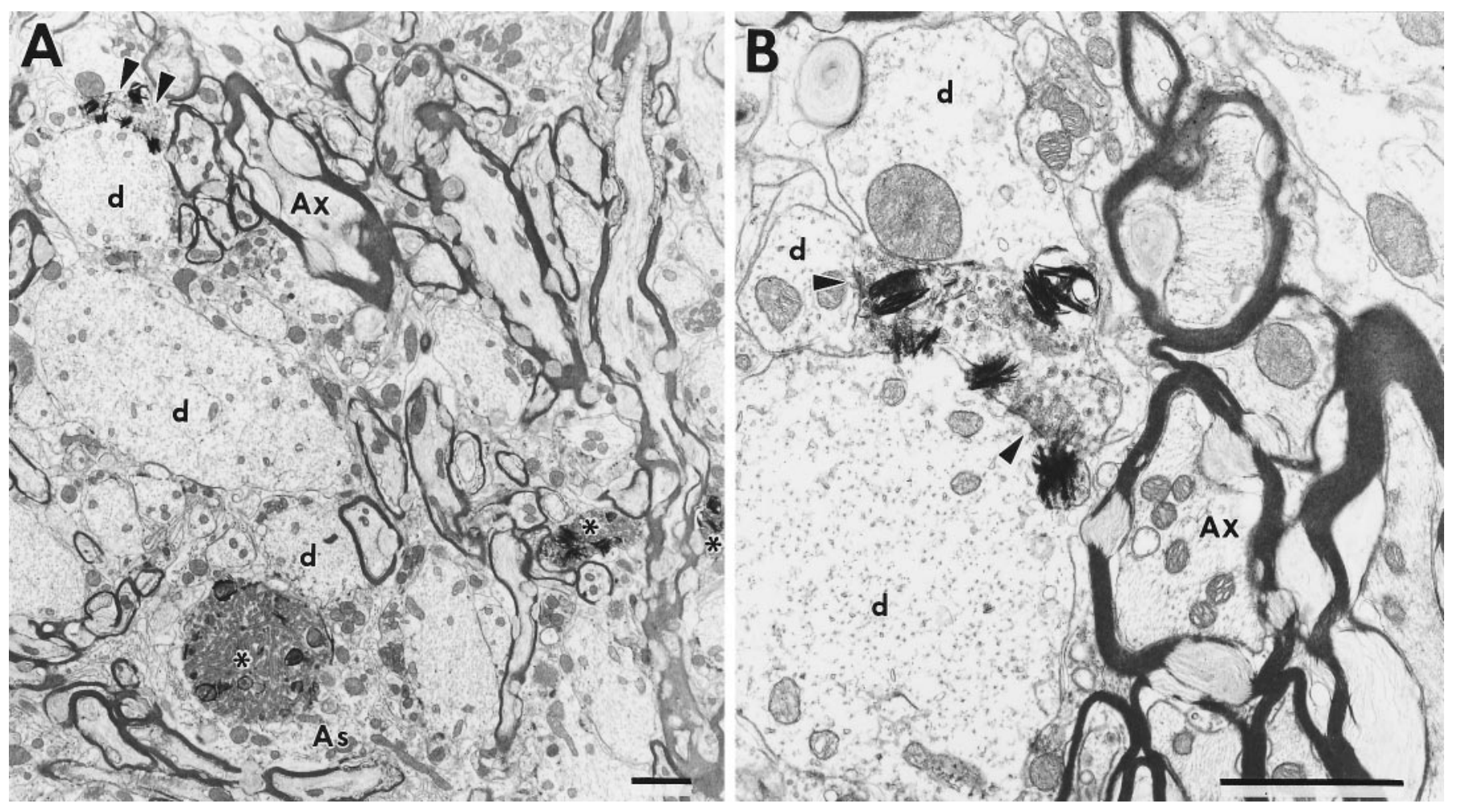

Figure 8. Electronmicrographs of labeled structures in the semimembranosus motoneuronal cell group of case 2337 (natural estrus). $A$ shows one or more axonal growth cones (asterisks in $A$ ), parts of an axonal growth cone, and a terminal profile (arrowheads). The growth cones contain densely packed mitochondria and do not form synaptic contacts. The labeled profile in $B$ is a magnification of the labeled terminal profile in $A$ (one section difference). It is filled with spherical synaptic vesicles and dense-core and large granulated vesicles, and forms asymmetrical synaptic junctions with two dendrites (arrowheads). $d$, Dendrite; $A s$, astrocyte; $A x$, axon. Scale bars, $1 \mu \mathrm{m}$.

cones in the semimembranosus motoneuronal cell group in estrous cats, which were never found in any of the nonestrous cats, demonstrates that the difference in number of labeled profiles is probably based on the formation of new NRA terminals. The finding that the percentage of labeled profiles with one or more synaptic junctions decreases in estrous as compared with nonestrous cases is in line with this hypothesis. Furthermore, electron microscopical examination of the semimembranosus cell group in estrous and nonestrous cases showed that the labeled profiles contained primarily spherical and dense-cored vesicles and formed asymmetrical synapses, suggesting a primarily excitatory role for the NRA-lumbosacral pathway (see Holstege, 1989). The NRA profiles can be classified as S- or NFs-type (Conradi, 1969; McLaughlin, 1972). Presently, a study is underway to find out whether the estrous increase in the number of labeled terminal profiles occurs at the expense of unlabeled ones or whether it is caused by a total increase in the number of terminal profiles (labeled and unlabeled) per unit area.

It is possible that estrogen increased the efficiency of WGAHRP transport, thus resulting in densely labeled axons in estrous and weakly labeled axons in nonestrous animals. Although this possibility cannot be excluded, it is unlikely for several reasons. (1) In both nonestrous and estrous animals, a dense NRA projection was present to the abdominal wall and pelvic floor motoneuronal cell groups. These findings indicate that NRA neurons excellently transport the tracer along their axons throughout the length of the spinal cord in nonestrous cases. Moreover, the few dispersed NRA axons in nonestrous cases were very well labeled. It seems unlikely that steroids selectively affect transport efficiency of only a subpopulation of NRA axons. (2) Light microscopically, in the lumbosacral cord of the nucleus ruber-injected cases, no differences in the density of labeling were observed between nonestrous and estrous animals. (3) In all estrous cases, many growth cones (labeled and unlabeled) were observed in the semimembranosus motoneuronal cell group. In contrast, in all samples of the nonestrous cases, only one example of a growth cone (unlabeled) was found in the semimembranosus motoneuronal cell group. (4) Systemic administration of androgen, which induces outgrowth of motoneuronal dendrites in adult rats (see Kurz et al., 1986), does not affect transport of cholera toxin-HRP by motoneurons (Leslie et al., 1991).

In summary, the number of probable excitatory NRA profiles in the semimembranosus motoneuronal cell group increases enormously in estrous cases as compared with nonestrous cases. The presence of labeled growth cones in estrous (natural as well as ovariectomized estrogen-treated) and the absence of such structures in nonestrous cats (natural as well as ovariectomized) suggest that the difference in density in the NRA-lumbosacral projection is based on estrogen-induced outgrowth or sprouting of NRA axons (Fig. 12).

\section{Possible mechanisms underlying sprouting of NRA axons}

The finding that estrogen induces outgrowth of the NRAlumbosacral pathway leads to the question of which mechanisms are involved in this process. The following possibilities underlying the axonal growth are discussed: activity of the NRA-lumbosacral pathway, effects of estrogen on induction of protein synthesis by genomic activation via intracellular estrogen receptors in neurons, 

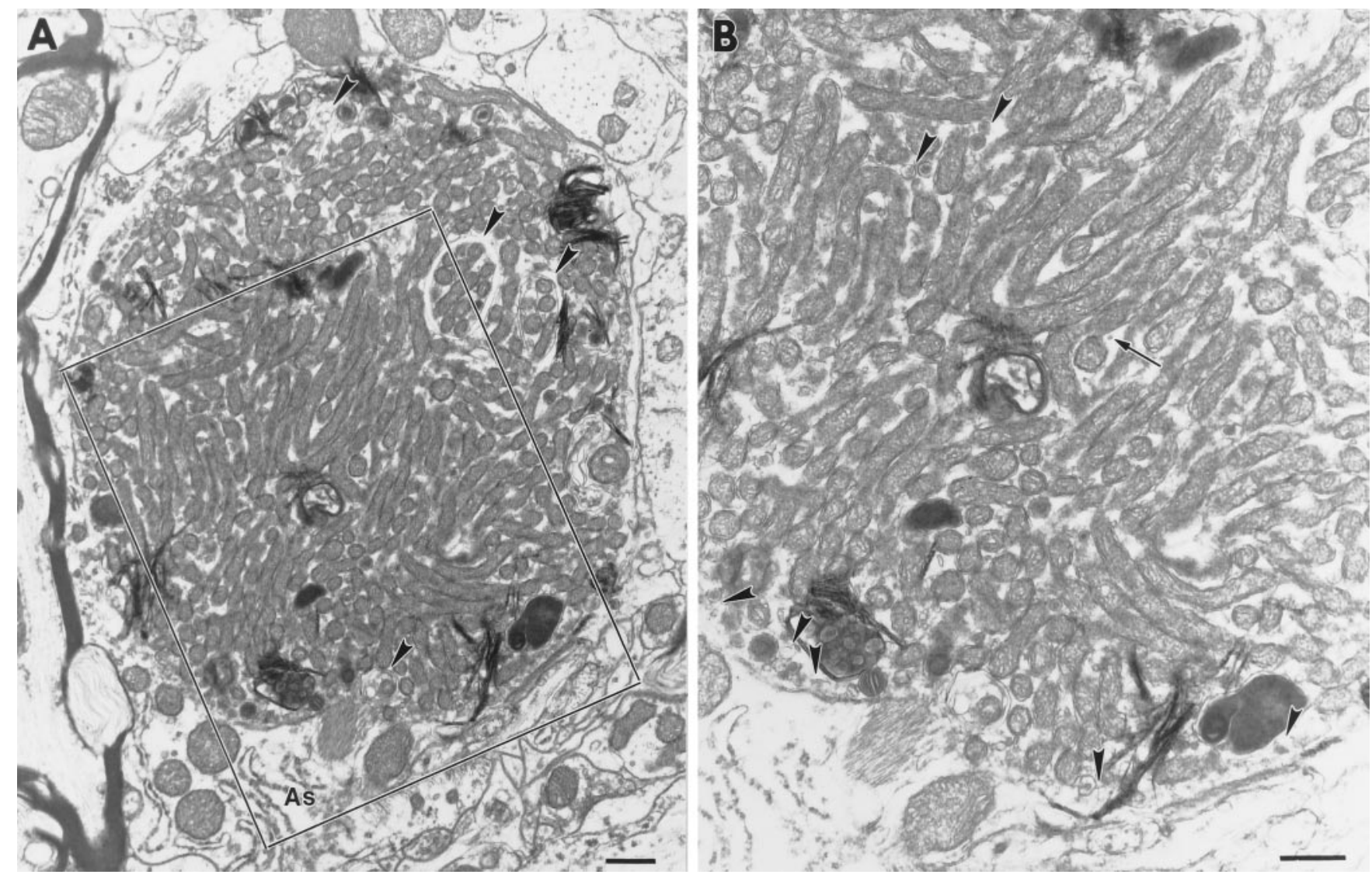

Figure 9. Electronmicrographs representing a labeled growth cone in the semimembranosus motoneuronal cell group of estrous case 2337 for a large part surrounded by astrocytes $(A s)$. The mitochondria in the labeled profile have a small diameter and are elongated and oriented in or transverse to the plane of the section. Small groups of mitochondria are sequestered within agranular membranes $(A$, arrowheads). Apart from the mitochondria and smooth membranes, the labeled profile contains a few electron-dense bodies, microtubuli $(B$, arrow), some spherical, dense-core, and large granulated vesicles $(B$, arrowheads), and an occasional coated vesicle. A majority of the vesicles are located in close proximity to the cytoplasmic membrane. Note that some TMB reaction product appears to be incorporated into the smooth membranes and plasma membrane. Scale bars, $0.5 \mu \mathrm{m}$.

muscles, and astroglia, and changing the membrane excitability via estrogen receptors in the cell membrane.

\section{Activity of the NRA-motoneuronal pathway}

Theoretically, activity of the NRA-motoneuronal pathway might induce the growth in this pathway. This is not a likely option, because estrogen administration alone does not activate this pathway. Only after adequate sensory stimuli, which are naturally evoked by a mounting male, does the female display the receptive posture. This activation only occurs when the female is in full estrous and not at all when she is in nonestrous. Thus, increased activity of the NRA pathway to hindlimb motoneuronal cell groups appears to take place after the outgrowth has taken place.

\section{Genomic activation via intracellular estrogen receptors}

Estrogen-induced protein synthesis is a relatively slow response (hours to days) (Pfaff and McEwen, 1983; Clark and Mani, 1994; Pfaff et al., 1994). It is mediated via intracellular receptors, which when bound to estradiol, activate a specific DNA target (Halachmi et al., 1994). The resulting newly synthesized proteins are transported down the axon (Pfaff and McEwen, 1983; Pfaff et al., 1984; Mobbs et al., 1988), where they are thought to be involved in plastic changes (see Pfaff et al., 1994). Estrogenrelated plasticity has been described in cell populations containing intracellular estrogen receptors (Pfaff and Keiner, 1973; Stumpf et al., 1975; Stumpf and Sar, 1976; Rees et al., 1980). These cell groups have a facilitating effect on lordosis behavior in adult mammals. Examples are the lateral septum (Miyakawa and Arai, 1987), ventrolateral part of the ventromedial hypothalamus (Carrer and Aoki, 1982), and PAG (Chung et al., 1988, 1990). Such plastic changes occur within $24-48 \mathrm{hr}$, in parallel with the estrous cycle in the rat and hamster (Olmos et al., 1989; Frankfurt et al., 1990; Meisel and Luttrell, 1990; Frankfurt and McEwen, 1991; Langub et al., 1994).

The question is whether a similar mechanism underlies axonal outgrowth in the NRA-lumbosacral pathway. Neither the NRA nor its target motoneuronal cell groups contain estrogen receptors or concentrate estrogen (Stumpf et al., 1975; Stumpf and Sar, 1976; Rees et al., 1980; Morrell et al., 1982) (E. Meijer, V. VanderHorst, and G. Holstege, unpublished observations). However, in the rat, the lateral PAG contains estrogen-concentrating neurons, some of which project to the caudal medulla oblongata (Corodimas and Morrell, 1990). In the cat, estrogen receptorcontaining PAG neurons target the NRA (V. VanderHorst, E. Meijer, and G. Holstege, unpublished observations). Other estrogen-concentrating structures in the forebrain, such as the ventrolateral part of the ventromedial hypothalamus, medial preoptic area, and amygdala, do not have direct connections with the NRA interneurons (Holstege, 1991). Possibly, the estrogen- 

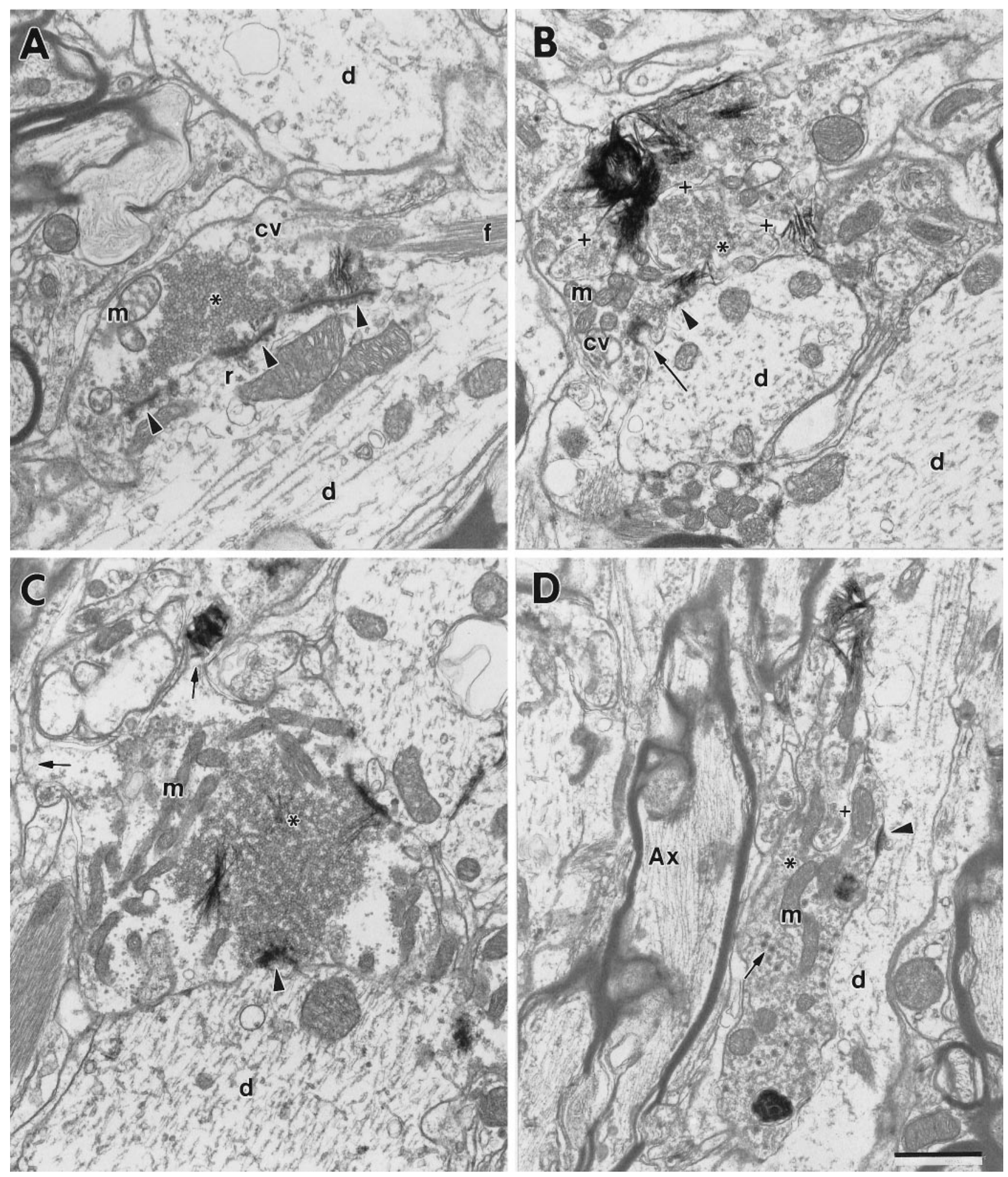

Figure 10. Electronmicrographs of labeled NRA axo-dendritic terminals in the semimembranosus motoneuronal cell group in estrous cases $2353(A), 2337(B$, $C$ ), and $2288(D)$. In $A$, a labeled terminal is shown that exhibits three asymmetrical complexes (arrowheads) with subsynaptic dense bodies. The profile contains a bundle of neurofilaments $(f)$, densely arranged spherical synaptic vesicles (asterisk), a few dense-core vesicles, and numerous coated vesicles, some of which seem to originate from double-membrane particles $(\mathrm{cv})$. The matrix of the mitochondria $(\mathrm{m})$ in the labeled profile is not as dense as that of the mitochondria in adjacent profiles. Postsynaptically, large mitochondria $(m)$, cisternae of agranular reticulum, and free ribosomes $(r)$ are present. $B$ shows a large labeled terminal containing large quantities of spherical synaptic vesicles (asterisk), coated vesicles $(\mathrm{cv})$, dense-core and large granulated vesicles, cisternae of smooth membranes $(+)$, and a small cluster of mitochondria $(m)$. The terminal forms asymmetrical complexes with a dendrite $($ arrowhead $)$ and a dendritic spine $($ arrow). $C$ demonstrates a large labeled terminal with many densely packed spherical vesicles (asterisk) and elongated mitochondria $(m)$ contacting a dendrite (arrowhead). The arrows indicate extensions of the terminal. In $D$, a labeled profile is present, establishing an asymmetrical synaptic contact (arrowhead) with a small dendrite $(d)$. The terminal contains mitochondria $(m)$, sheets of smooth membranes $(+)$, dense-core and large granulated vesicles $($ arrow), spherical vesicles, and numerous small cisternae of agranular reticulum. Scale bar, $1 \mu \mathrm{m}$. 


\section{Non-estrous}

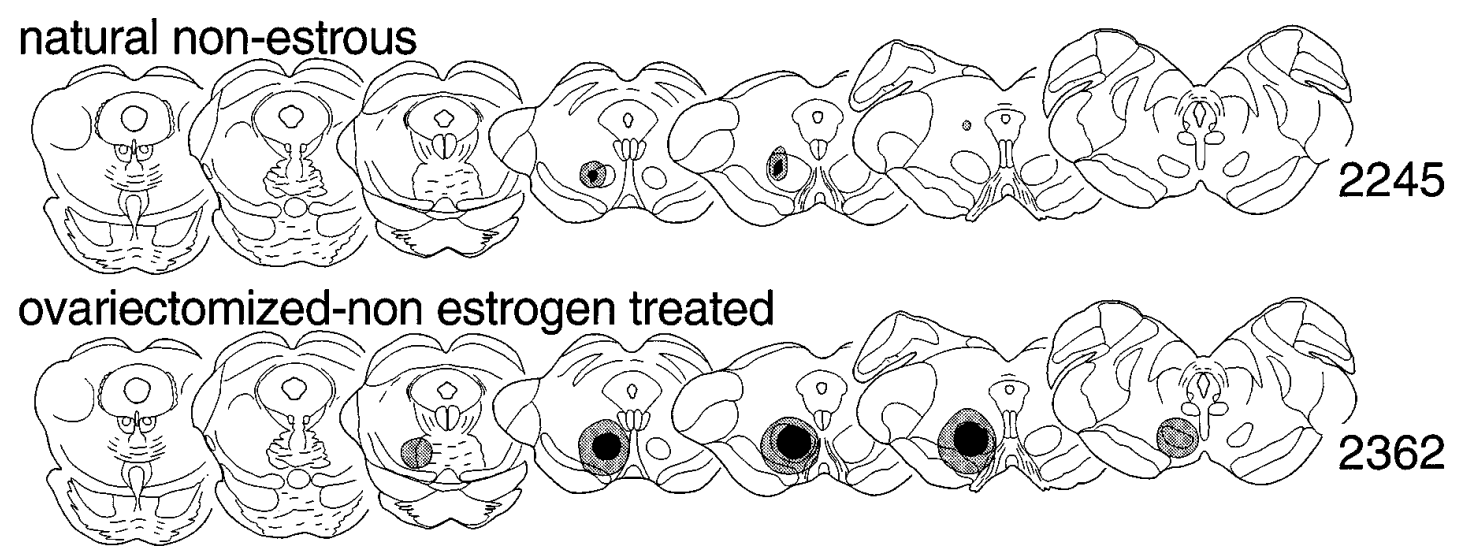

\section{Estrous}

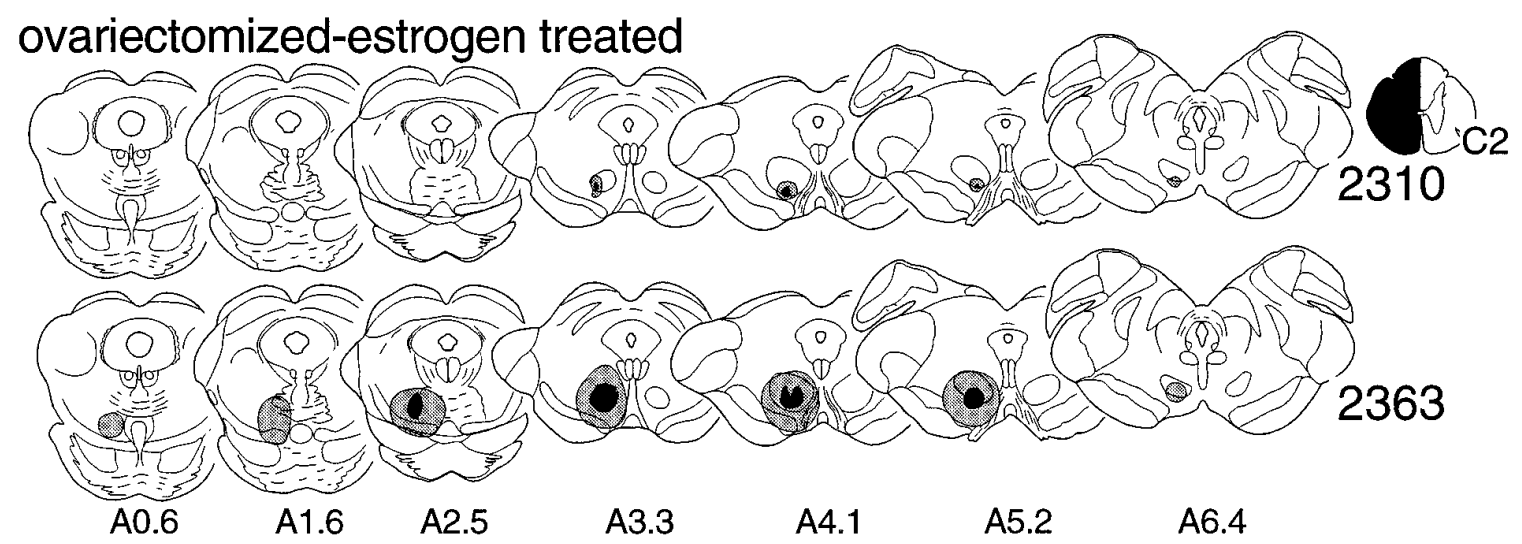

Figure 11. Overview of the WGA-HRP injection sites involving the red nucleus in estrous and nonestrous cases. $A 0.6-A 6.4$ indicate the anteriorposterior coordinates according to the atlas of Berman (1968).

concentrating neurons in the PAG play a major role in preparing the NRA-lumbosacral pathway for its specific action during lordosis behavior.

\section{Muscles}

Another possibility is that estrogen exerts an effect on the NRAmotoneuronal pathway via the muscles involved (for review, see Haydon and Zoran, 1994). In this respect, in humans it has been demonstrated that the pelvic floor muscle levator ani, but not the rectus abdominis muscle, contain estrogen receptors (Smith et al., 1990, 1993). This would correspond with the finding that, at least in the cat, the motoneuronal cell groups innervating pelvic floor muscles receive NRA afferents (Holstege and Tan, 1987; VanderHorst and Holstege, 1995), whereas the rectus abdominus motoneurons are not targeted by the NRA (Holstege, 1989). Possibly, under high levels of estrogen, estrogen receptor-containing muscles send a retrograde signal to their motoneurons, which in turn induce outgrowth of NRA axons. This option, in which the NRA target motoneurons play a role in the outgrowth of NRA axons, is supported by the finding that the outgrowth is directed to only these motoneurons.

Glia

In addition to its action via estrogen receptors in neurons or muscles, estrogen might also have an effect on axonal growth and the formation of new terminals via astroglia (see Theodosis and Poulain, 1993). Intracellular estrogen receptors have been demonstrated in astrocytes in the medial preoptic area and median eminence (Langub and Watson, 1992). In the present study, astrocytes were frequently observed in close proximity to labeled profiles (see Figs. 8, 9).

\section{Estrogen effects on membrane excitability}

Estrogen has also been shown to change the membrane excitability of neurons within minutes (see Alcaraz et al., 1969; Yagi, 1970; Kelly et al., 1977; Dufy et al., 1979; Levesque and Di Paolo, 1988; Schumacher, 1990; Smith, 1994). Such rapid effects have been described for numerous cell groups such as the anterior hypothalamus (Kawakami et al., 1970; Cross and Dyer, 1972; Alcaraz et al., 1969), medial amygdala (Nabekura et al., 1986), hippocampus (Wong and Moss, 1991, 1992), neostriatum (Levesque and Di Paolo, 1988; Thompson and Moss, 1994; Mermelstein et al., 1996), and cerebellum (S. S. Smith et al., 1987, 1989). This effect seems to be mediated via cellular membrane receptors (Schumacher, 1990) that affect L-type calcium channels (Mermelstein et al., 1996). The extent to which this mechanism plays a role in the NRA axonal outgrowth is not known. 


\section{Non-estrous}

\section{Estrous}

Figure 12. Schematic illustration of the estrogen-induced axonal sprouting of NRA fibers to lumbosacral motoneurons. The number of terminals shown reflects the difference in NRA terminals that have been counted.
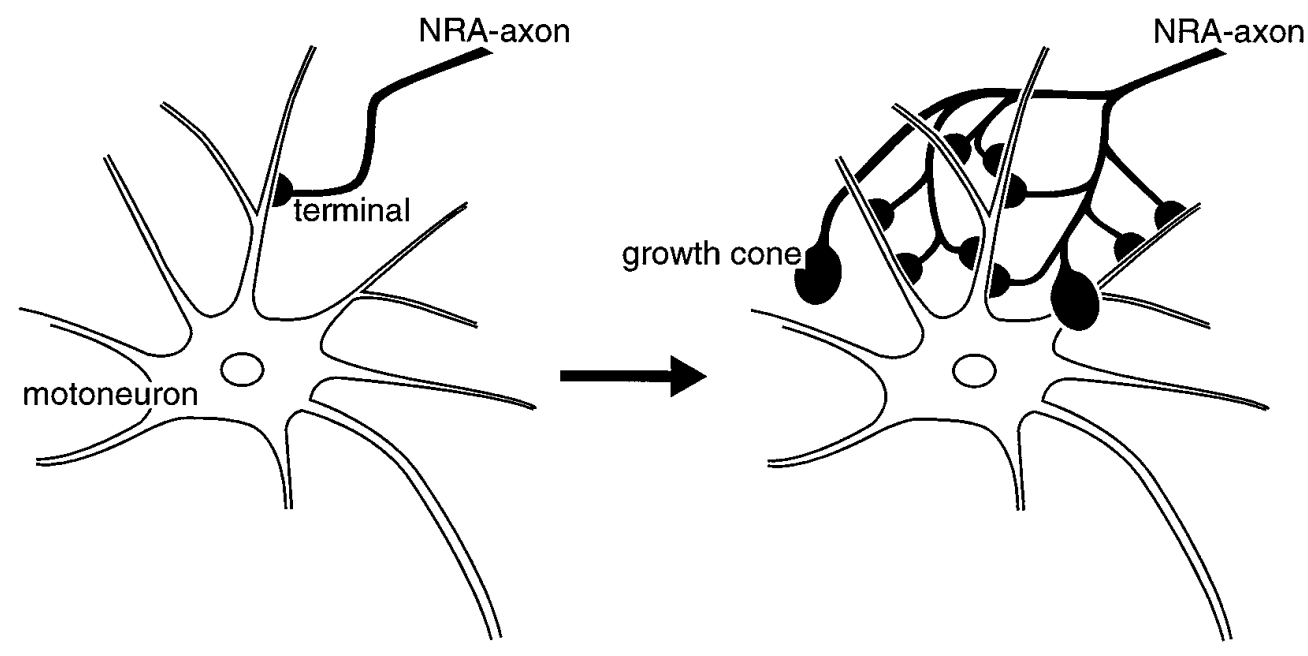

\section{Functional implications of estrogen-induced axonal sprouting in the NRA-lumbosacral pathway}

The female sex steroid estrogen has been shown to induce dendritic growth or synaptic plasticity in mammalian mid- and forebrain structures (see, for example, Matsumoto and Arai, 1979; Carrer and Aoki, 1982; Miyakawa and Arai, 1987; Chung et al., 1988, 1990; Langub et al., 1989, 1994; Frankfurt et al., 1990; Meisel and Luttrell, 1990; Frankfurt and McEwen, 1991; Matsumoto, 1991; Woolley and McEwen, 1992a,b, 1994; Garcia-Segura et al., 1994) as well as in non-neuronal structures such as the uterus (Burrows, 1949; Reynolds, 1951) (for review, see Clark and Mani, 1994). In the adult mammalian spinal cord, male sex steroids are known to increase the length of motoneuronal dendrites (Kurz et al., 1986). These changes in dendritic length are acompanied by differences in synaptic input of unidentified origin (Leedy et al., 1987; Matsumoto et al., 1988). The present study is the first to show that the female sex steroid estrogen induces axonal outgrowth of a precisely identified pathway in the adult mammalian CNS. This outgrowth takes place in a long brainstemspinal motor tract, which is thought to represent the final common pathway for lordosis. The effect of estrogen on this pathway seems to be rather specific, because no estrogen-related differences could be detected in the rubrospinal motor tract.

These findings are in line with the notion that estrogen or other sex steroids are necessary for activation of the reproductive neural circuitry, which appears to be latently present in nonestrous animals.

\section{REFERENCES}

Alcaraz M, Guzman-Flores C, Salas M, Beyer C (1969) Effect of estrogen on the responsivity of hypothalamic and mesencephalic neurons in the female cat. Brain Res 15:439-446.

Bandler R, Carrive P, Zhang SP (1991) Integration of somatic and autonomic reactions within the midbrain periaqueductal gray: viscerotopic, somatotopic and functional organization. Prog Brain Res 87:269-305.

Beach FA (1948) Hormones and behavior: a survey of interrelationships between endocrine secretions and patterns of overt response. New York: Hoeber.

Berman AL (1968) The brain stem of the cat. A cytoarchitectonic atlas with stereotaxic coordinates. Madison, WI: University of Wisconsin.

Bridgman PC, Dailey ME (1989) The organization of mysosin and actin in rapid frozen nerve growth cones. J Cell Biol 108:95-109.
Bunge MB (1973) Fine structure of nerve fibers and growth cones of isolated sympathetic neurons in culture. J Cell Biol 56:713-735.

Burrows H (1949) Biological actions of sex hormones. Cambridge: Cambridge UP.

Carrer HF, Aoki A (1982) Ultrastructural changes in the hypothalamic ventromedial nucleus of ovariectomized rats after estrogen treatment. Brain Res 240:221-233.

Chung SK, Pfaff DW, Cohen RS (1988) Estrogen-induced alterations in synaptic morphology in the midbrain central gray. Exp Brain Res 69:522-530.

Chung SK, Cohen RS, Pfaff DW (1990) Transneuronal degeneration in the midbrain central gray following chemical lesions in the ventromedial nucleus: a qualitative and quantitative analysis. Neurosci 38:409-426.

Clark JH, Mani SK (1994) Actions of ovarian steroid hormones. In: The physiology of reproduction, Vol 1 (Knobil E, Neill JD, eds), pp 10111059. New York: Raven.

Conradi S (1969) On motoneuron synaptology in adult cats. Acta Physiol Scand [Suppl] 332:1-115.

Corodimas KP, Morrell JI (1990) Estradiol-concentrating forebrain and midbrain neurons project directly to the medulla. J Comp Neurol 291:609-620.

Cross BA, Dyer RG (1972) Ovarian modulation of unit activity in the anterior hypothalamus of the cyclic rat. J Physiol (Lond) 222:25P.

Davis L, Dou P, DeWit M, Kater SB (1992) Protein synthesis within neuronal growth cones. J Neurosci 12:4867-4877.

Dawson AB, Friedgood HB (1940) The time and sequence of preovulatory changes in the cat ovary after mating or mechanical stimulation of the cervix uteri. Anat Rec 76:411-424.

Dufy B, Vincent J-D, Fleury H, DuPasquier P, Gourdji D, Tixier-Vidal A (1979) Membrane effects of thyrotropin-releasing hormone and estrogen shown by intracellular recording from pituitary cells. Science 204:509-511.

Ellenberger HH, Feldman JL (1990) Brainstem connections of the rostral ventral respiratory group of the rat. Brain Res 513:35-42.

Feldman JL (1986) Neurophysiology of breathing in mammals. In: Handbook of physiology, Sec 1, The nervous system, Vol IV, Intrinsic regulatory systems of the brain (Bloom FE, ed), pp 463-524. Bethesda, MD: American Physiological Society.

Feldman JL, Loewy AD, Speck DF (1985) Projections from the ventral respiratory group to phrenic and intercostal motoneurons in cat: an autoradiographic study. J Neurosci 5:1993-2000.

Frankfurt M, McEwen BS (1991) Estrogen increases axodendritic synapses in the VMN of rats after ovariectomy. NeuroReport 2:380-382.

Frankfurt M, Gould E, Woolley CS, McEwen BS (1990) Gonadal steroids modify dendritic spine density in ventromedial hypothalamic neurons: a Golgi study in the adult rat. Neuroendocrinology 51:530-535.

Fukuda H, Fukai K (1986) Location of the reflex centre for straining elicited by activation of pelvic afferent fibres of decebrate dogs. Brain Res 380:287-296. 
Garcia-Segura LM, Chowen JA, Parducz A, Naftolin F (1994) Gonadal hormones as promoters of structural synaptic plasticity: cellular mechanisms. Prog Neurobiol 44:279-307.

Gerrits PO, Holstege G (1996) Pontine and medullary projections to the nucleus retroambiguus: a WGA-HRP and autoradiographic tracing study in the cat. J Comp Neurol 373:173-185.

Halachmi S, Marden E, Martin G, MacKay H, Abbondanza C, Brown M (1994) Estrogen receptor-associated proteins: possible mediators of hormone-induced transcription. Science 264:1455-1458.

Haydon PG, Zoran MJ (1994) Retrograde regulation of presynaptic development during synaptogenesis. J Neurobiol 25:694-706.

Henry MA, Westrum LE, Johnson LR (1985) Enhanced ultrastructural visualization of the horseradish peroxidase-tetramethylbenzidine reaction product. J Histochem Cytochem 33:1256-1259.

Holstege G (1989) Anatomical study of the final common pathway for vocalization in the cat. J Comp Neurol 284:242-252.

Holstege G (1991) Descending motor pathways and the spinal motor system: limbic and non-limbic components. Prog Brain Res 87:307-412.

Holstege G, Kuypers HGJM (1982) The anatomy of brain stem pathways to the spinal cord in the cat. A labeled amino acid tracing study. Prog Brain Res 57:145-175.

Holstege G, Tan J (1987) Supraspinal control of motoneurons innervating the striated muscles of the pelvic floor including urethral and anal sphincters in the cat. Brain 110:1323-1344.

Holstege JC (1989) Brainstem projections to motoneurons in the lumbar spinal cord. An ultrastructural study in the rat. Rotterdam: Thesis Erasmus University.

Kawakami M, Terasawa E, Ibuki T (1970) Changes in multiple unit activity of the brain during the estrous cycle. Neuroendocrinology 6:30.

Kelly MJ, Moss RL, Dudley CA (1977) The effects of microelectrophoretically applied estrogen, cortisol and acetylcholine on medial preoptic-septal unit activity throughout the estrous cycle of the female rat. Exp Brain Res 30:53-64.

Knyihar-Csillik E, Rakic P, Csillik B (1986) Reactive synapto-neogenesis in the upper dorsal horn of the adult primate: regenerative or collateral sprouting? In: Development and plasticity in the mammalian spinal cord (Goldberger M, Gorio M, Murray M, eds), pp 191-210. Padova, Italy: Liviana.

Kurz EM, Sengelaub DR, Arnold AP (1986) Androgens regulate the dendritic length of mammalian motoneurons in adulthood. Science 232:395-398.

Langub MC, Watson RE (1992) Estrogen receptor-immunoreactive glia, endothelia, and ependyma in guinea pig preoptic area and median eminence: electron microscopy. Endocrinology 130:364-372.

Langub Jr MC, Maley BE, Watson Jr RE (1994) Estrous cycle-associated axosomatic synaptic plasticity upon estrogen receptive neurons in the rat preoptic area. Brain Res 641:303-310.

Leedy MG, Beattie MS, Bresnahan JC (1987) Testosterone-induced plasticity of synaptic inputs to adult mammalian motoneurons. Brain Res 424:386-390.

Leslie M, Forger NG, Breedlove SM (1991) Does androgen affect axonal transport of cholera toxin HRP in spinal motoneurons? Neurosci Lett 126:199-202.

Levesque D, DiPaolo T (1988) Rapid conversion of high into low striatal D2-dopamine receptor agonist binding states after an acute physiological dose of $17 \beta$-estradiol. Neurosci Lett 88:113-118.

Matsumoto A (1991) Synaptogenic action of sex steroids in developing and adult neuroendocrine brain. Psychoneuroendocrinology 16:25-40.

Matsumoto A, Arai Y (1979) Synaptogenic effect of estrogen on the hypothalamic arcuate nucleus of the adult female rat. Cell Tissue Res 198:427-433.

Matsumoto A, Micevych PE, Arnold AP (1988) Androgen regulates synaptic input to motoneurons of the adult rat spinal cord. J Neurosci 8:4168-4176.

McLaughlin BJ (1972) The fine structure of neurons and synapses in the motor nuclei of the cat spinal cord. J Comp Neurol 144:429-460.

Meisel RL, Luttrell VR (1990) Estradiol increases the dendritic length of ventromedial hypothalamic neurons in female Syrian hamsters. Brain Res Bull 25:165-168.

Mermelstein PG, Becker JB, Surmeier DJ (1996) Estradiol reduces calcium currents in rat neostriatal neurons via a membrane receptor. J Neurosci 16:595-604.

Merrill EG (1970) The lateral respiratory neurones of the medulla: their associations with nucleus ambiguus, nucleus retroambigualis, the spinal accessory nucleus and the spinal cord. Brain Res 24:11-28.
Merrill EG (1971) The descending pathways from the lateral respiratory neurons in cats. J Physiol (Lond) 218:82-83.

Merrill EG (1974) Finding a respiratory function for the medullary respiratory neurons. In: Essays on the nervous system (Bellairs R, Gray EG, eds), pp 451-486. Oxford: Clarendon.

Mesulam M-M (1982) Principles of horseradish peroxidase neurohistochemistry and their applications for tracing neural pathways-axonal transport, enzyme histochemistry and light microscopic analysis. In: Tracing neural connections with horseradish peroxidase (Mesulam M-M, ed), pp 1-151. Chichester, UK: Wiley.

Michael RP (1960) Observations upon the sexual behaviour of the domestic cat (Felis catus L.) under laboratory conditions. Behaviour 18:1-24.

Miller AD, Tan LK, Suzuki I (1987) Control of abdominal and expiratory intercostal muscle activity during vomiting: role of ventral respiratory group expiratory neurons. J Neurophysiol 57:1854-1866.

Miller AD, Tan LK, Lakos SF (1989) Brainstem projections to cats' upper lumbar spinal cord: implications for abdominal muscle control. Brain Res 493:348-356.

Miller AD, Nonaka S, Siniaia MS, Jakus J (1995) Multifunctional ventral respiratory group: bulbospinal expiratory neurons play a role in pudendal discharge during vomiting. J Auton Nerv Syst 54:253-260.

Miyakawa M, Arai Y (1987) Synaptic plasticity to estrogen in the lateral septum of the adult male and female rats. Brain Res 436:184-188.

Mobbs CV, Harlan RE, Burrous MR, Pfaff DW (1988) An estradiolinduced protein synthesized in the ventral medial hypothalamus and transported to the midbrain central gray. J Neurosci 8:113-118.

Morrell JI, Wolinsky TD, Krieger MS, Pfaff DW (1982) Autoradiographic identification of estradiol-concentrating cells in the spinal cord of the female rat. Exp Brain Res 45:144-50.

Nabekura J, Oomura Y, Minami T, Mizuno Y, Fukuda A (1986) Mechanism of the rapid effect of $17 \beta$-estradiol on medial amygdala neurons. Science 233:226-228.

Ogawa S, Kow LM, McCarthy MM, Pfaff DW, Schwartz-Giblin S (1991) Midbrain PAG control of female reproductive behavior: in vitro electrophysiological characterization of actions of lordosis-relevant substances. In: The midbrain periaqueductal gray matter (Depaulis A, Bandler R, eds), pp 211-235. New York: Plenum.

Olmos G, Naftolin F, Perez J, Tranque PA, Garcia-Segura LM (1989) Synaptic remodeling in the rat arcuate nucleus during the estrous cycle. Neuroscience 32:663-667.

Olszewski J, Baxter D (1954) Cytoarchitecture of the human brain stem. Philadelphia: Lippincott.

Olucha F, Martinez-Garcia F, Lopez-Garcia C (1985) A new stabilizing agent for the tetramethyl benzidine (TMB) reaction product in the histochemical detection of horseradish peroxidase (HRP). J Neurosci Methods 13:131-138.

Paxinos G, Watson C (1986) The rat brain stereotaxic coordinates. Sydney: Academic.

Peters A, Palay SL, Webster HdeF (1991) The fine structure of the nervous system. Neurons and their supporting cells, 3rd ed. New York: Oxford UP.

Pfaff DW, Keiner M (1973) Atlas of estradiol-concentrating cells in the central nervous system of the female rat. J Comp Neurol 151:121-158.

Pfaff DW, McEwen BS (1983) Actions of estrogens and progestins on nerve cells. Science 219:808-14.

Pfaff DW, Rosello L, Blackburn P (1984) Proteins synthesized in medial hypothalamus and transported to midbrain in estrogen-treated female rats. Exp Brain Res 57:204-207.

Pfaff DW, Schwartz-Giblin S, McCarthy MM, Kow LM (1994) Cellular and molecular mechanisms of female reproductive behaviors. In: The physiology of reproduction (Knobil E, Neill JD, eds), pp 107-220. New York: Raven.

Rees HD, Switz GM, Michael RP (1980) The estrogen-sensitive neural system in the brain of female cats. J Comp Neurol 193:789-804.

Rees RP, Bunge MB, Bunge RP (1976) Morphological changes in the neuritic growth cone and target neuron during synaptic junction development in culture. J Cell Biol 68:240-263.

Reynolds SRM (1951) Determinants of uterine growth and activity. Physiol Rev 1:244-273.

Romanes GJ (1951) The motor cell columns of the lumbo-sacral spinal cord of the cat. J Comp Neurol 94:313-363.

Romanes GJ (1964) The motor pools of the spinal cord. Prog Brain Res 11:93-119.

Sakuma Y, Pfaff DW (1979a) Facilitation of female reproductive behav- 
ior from mesencephalic central gray in the rat. Am J Physiol 237:R278-R284.

Sakuma Y, Pfaff DW (1979b) Mesencephalic mechanisms for integration of female reproductive behavior in the rat. Am $J$ Physiol 237:R285-R290.

Schumacher M (1990) Rapid membrane effects of steroid hormones: an emerging concept in neuroendocrinology. Trends Neurosci 13:359-362.

Smith JC, Morrison DE, Ellenberger HH, Otto MR, Feldman JL (1989) Brainstem projections to the major respiratory neuron populations in the medulla of the cat. J Comp Neurol 281:69-96.

Smith P, Heimer G, Norgren A, Ulmsten U (1990) Steroid hormone receptors in pelvic muscles and ligaments in women. Gynecol Obstet Invest 30:27-30.

Smith P, Heimer G, Norgren A, Ulmsten U (1993) Localization of steroid hormone receptors in the pelvic muscles. J Obstet Gynecol Reprod Biol 50:83-85.

Smith SS (1994) Female sex steroid hormones: from receptors to networks to performance-actions on the sensorimotor system. Prog Neurobiol 44:55-86.

Smith SS, Waterhouse BD, Woodward DJ (1987) Sex steroid effects on extrahypothalamic CNS. I. Estrogen augments neuronal responsiveness to iontophoretically applied glutamate in the cerebellum. Brain Res 422:40-51.

Smith SS, Woodward DJ, Chapin JK (1989) Sex steroids modulate motor-correlated increases in cerebellar discharge. Brain Res 476:307-316.

Steward O, Falk PM (1986) Protein synthetic machinery at postsynaptic sites during synaptogenesis: a quantitative study of the association between polyribosomes and developing synapses. J Neurosci 6:412-423.

Steward O, Falk PM (1991) Selective localization of polyribosomes beneath developing synapses: a quantitative analysis of the relationships between polyribosomes and developing synapses in the hippocampus and dentate gyrus. J Comp Neurol 314:545-557.

Stumpf WE, Sar M (1976) Steroid hormone target sites in the brain: the differential distribution of estrogen, progestin, androgen and glucocorticosteroid. J Steroid Biochem 7:1163-1170.

Stumpf WE, Sar M, Keefer DA (1975) Atlas of estrogen target cells in rat brain. In: Anatomical neuroendocrinology. Paper presented at International Conference on Neurobiology of CNS-Hormone Interactions, Chapel Hill, 1974, pp 104-119. Basel: Karger.

Tennyson VM (1970) The fine structure of the axon and growth cone of the dorsal root neuroblast of the rabbit embryo. J Cell Biol 44:62-79.

Theodosis DT, Poulain DA (1993) Activity-dependent neuronal-glial and synaptic plasticity in the adult mammalian hypothalamus. Neuroscience 57:501-535.

Thompson TL, Moss RL (1994) Estrogen regulation of dopamine release in the nucleus accumbens: genomic- and nongenomic-mediated effects. J Neurochem 62:1750-1756.
VanderHorst VGJM, Holstege G (1995) Caudal medullary pathways to lumbosacral motoneuronal cell groups in the cat: evidence for direct projections possibly representing the final common pathway for lordosis. J Comp Neurol 359:457-475.

VanderHorst VGJM, Holstege G (1996) A concept for the final common pathway of vocalization and lordosis behavior in the cat. Prog Brain Res 107:327-341.

VanderHorst VGJM, Holstege G (1997a) The organization of lumbosacral motoneuronal cell groups innervating hindlimb, pelvic floor and axial muscles in the cat. J Comp Neurol, in press.

VanderHorst VGJM, Holstege G (1997b) Nucleus retroambiguus projections to lumbosacral motoneuronal cell groups in the male cat. J Comp Neurol, in press.

VanderHorst VGJM, DeWeerd H, Holstege G (1994) Direct projections from the nucleus retroambiguus to hindlimb motoneurons; a combined electron- and lightmicroscopic study in the cat. Neurosci Abstr 2:1584.

Vaughn JE, Sims TJ (1978) Axonal growth cones and developing axonal collaterals form synaptic junctions in embryonic mouse spinal cord. J Neurocytol 7:337-363.

Vinores SA, Herman MM, Rubinstein LJ, Marangos PJ (1984) Electron microscopic localization of neuron-specific enolase in rat and mouse brain. J Histochem Cytochem 32:1295-1302.

Wild JM (1993) The avian nucleus retroambigualis: a nucleus for breathing, singing and calling. Brain Res 606:319-324.

Wong M, Moss RL (1991) Electrophysiological evidence for a rapid membrane action of the gonadal steroid, $17 \beta$-estradiol, on CA1 pyramidal neurons in the rat hippocampus. Brain Res 543:148-152.

Wong M, Moss RL (1992) Long-term and short-term electrophysiological effects of estrogen on the synaptic properties of hippocampal CA1 neurons. J Neurosci 12:3217-3225.

Woolley CS, McEwen BS (1992a) Estradiol mediates fluctuation in hippocampal synapse density during the estrous cycle in the adult rat. J Neurosci 12:2549-2554.

Woolley CS, McEwen BS (1992b) Estradiol regulates hippocampal dendritic spine density via an $N$-methyl-D-aspartate receptor-dependent mechanism. J Neurosci 14:7680-7687.

Yagi K (1970) Effects of estrogen on the unit activity of the rat hypothalamus. J Physiol Soc Jpn 32:692.

Yamada KM, Spooner BS, Wessells NK (1971) Ultrastructure and function of growth cones and axons of cultured nerve cells. J Cell Biol 49:614-635.

Young WC (1961) The hormones and mating behavior. In: Sex and internal secretions (Young WC, ed). Baltimore: Williams \& Wilkins.

Zhang SP, Davis PJ, Carrive P, Bandler R (1992) Vocalization and marked pressor effect from the region of the nucleus retroambigualis in the caudal ventrolateral medulla of the cat. Neurosci Lett 140:103-107. 